\title{
La protección de la capacidad a través de la autonomía de la voluntad en el Derecho chileno y comparado*
}

\section{Yasna Otárola Espinoza ${ }^{* *}$}

Resumen: El artículo tiene por objetivo resolver si en el sistema chileno una persona capaz podría designar anticipadamente, en virtud de la autonomía de la voluntad, a otra que se hará cargo del cuidado de su persona y bienes, esto es, nombrar una persona para cuando ya no esté en situación de protegerse a sí misma, de modo que su familia no sea obligada a recurrir a procedimientos judiciales de incapacitación, y, de ser posible, determinar cuál podría ser la figura jurídica idónea para que las personas puedan expresar esta voluntad.

Palabras clave: Autonomía de la voluntad, incapacidad, mandato.

\section{The Protection of Capacity through Autonomy Judgement in Chilean and Comparative Law}

Aвstract: The aim of the article is to resolve whether a capable person in the Chilean system could designate in advance that another person will take care of

El artículo es parte del proyecto de investigación posdoctoral llevado a cabo en la Universidad Autónoma de Madrid, año 2017 , adjudicado por la profesora internamente en la Universidad Central de Chile. Fecha de recepción: 27 de febrero de 2017 . Fecha de aceptación: 22 de mayo de 20I7. Para citar el artículo: Otárola Espinoza, Y., "La protección de la capacidad a través de la autonomía de la voluntad en el Derecho chileno y comparado", Revista de Derecho Privado, Universidad Externado de Colombia, n. ${ }^{\circ} 33$, julio-diciembre de 2017 , I3-49.

DOI: https://doi.org/I0.1860I/or 234366.n33.02

** Doctora en Derecho y magíster, Pontificia Universidad Católica de Chile, Chile. Directora del área de Derecho Privado de la Universidad Central de Chile, Santiago, Chile. Las líneas de investigación de la autora son persona y daños. Recientemente publicó el libro Incumplimiento de los deberes matrimoniales y responsabilidad civil, Reus, 20I6. Contacto: yasna.otarola@ucentral.cl 
their person and property. That is to say, the possibility to appoint a person for the moment in which the person is not in a position to protect herself. Thus, the family is not forced to resort to legal incapacitation proceedings. Finally, the paper tries to determine the suitable legal form for elderly people to express this will.

KeYword: Autonomy judgement, independence, incapacity, elderly people, mandate.

\section{Introducción}

La Constitución chilena vigente asegura, garantiza y promueve los derechos esenciales de la persona humana, de acuerdo con los artículos I inciso I. $.^{\circ}, 5$ inciso $2 .^{\circ}$ y ig de la Carta fundamental. En ese sentido, indica que "las personas nacen libres e iguales en dignidad y derechos. También, que el Estado está al servicio de la persona humana, para lo cual debe contribuir a crear las condiciones sociales que permitan a todos y a cada uno de los integrantes de la comunidad nacional su mayor realización espiritual y material posible [...]”. De modo que la persona constituye el objetivo y la finalidad de la actuación estatal en el sistema jurídico chileno, el poder público está al servicio de la persona, actúa en función del desarrollo de sus derechos fundamentales. Los cuales permiten concretar la libertad y la igualdad de derechos entre las personas. En ese empeño, suscribió en r 990 la Convención de los derechos del niño, como marco regulador de la relación del Estado de Chile con la infancia y, aunque todavía no cuenta con una ley de protección integral de los derechos de los niños, ha avanzado en la protección de la primera infancia. De modo tal que lentamente ha incorporado la Convención al ordenamiento interno ${ }^{\mathrm{I}}$. En efecto, a través de diversas reformas

I Por medio de la Ley I9.585 de I 998 que elimina la distinción entre niños según su nacimiento dentro o fuera del matrimonio, que modifica el Código Civil y otros cuerpos legales en materia de filiación. Ley I 9.876 de 2003 que establece la obligatoriedad y gratuidad de la educación media. Ley I 9.966 de 2004 sobre régimen de garantías en salud (GEs). Ley I 9.968 de 2004 que crea los tribunales de familia. Ley 20.084 de 2005 sobre responsabilidad penal adolescente. Ley 20.066 de 2005 sobre violencia intrafamiliar. Ley 20.379 de 2009 sobre la instalación del subsistema de Protección Integral a la Infancia, Chile Crece Contigo. Ley 20.442 de 20 Io que establece normas sobre igualdad de oportunidades e inclusión social de personas en situación de discapacidad. Ley 20.529 de 20 I s sobre el sistema nacional de aseguramiento de la calidad de la educación. Ley 20.536 de 20 I I que establece las normas de promoción de la buena convivencia escolar y de prevención de toda forma de violencia en las escuelas. Ley 20.539 de 20 I I, que modifica el Código del Trabajo, que establece regulaciones al trabajo de menores de edad, prohibiendo a los menores de 18 años todo trabajo nocturno en establecimientos industriales y comerciales. Ley 20.545 de 20 i I sobre protección a la maternidad, extensión del posnatal para las madres e incorporación del permiso posnatal parental. Ley 20.526 de 20 i I que sanciona el acoso sexual infantil, pornografía y posesión de material pornográfico infantil. Ley 20.507 de 20 I q que tipifica el tráfico y trata de personas como delito. Ley 20.594 de 20 I 2 establece inhabilidades a los condenados por delitos sexuales contra niños, niñas y adolescentes. Ley 20.7 Io 
reconoció a los niños como sujetos de derecho y por ende el derecho de los niños a tomar decisiones, siempre que posean el suficiente juicio para comprender el acto que realizan, o sea la capacidad de entendimiento y el juicio para comprender el alcance y las consecuencias del acto de que se trate y adoptar decisiones responsables. En fin, promover su autonomía como sujeto.

También, se obligó a través de la Convención Interamericana sobre Derechos Humanos de las personas mayores a "promover, proteger y asegurar el reconocimiento y el pleno goce y ejercicio, en condiciones de igualdad, de todos los derechos humanos y libertades fundamentales de la persona mayor [...]"2. Reconoció el derecho de la persona mayor a tomar decisiones, a la definición de su plan de vida, a desarrollar una vida autónoma e independiente, conforme a sus tradiciones y creencias, en igualdad de condiciones, y a disponer de mecanismos para poder ejercer sus derechos.

Del mismo modo, hace un tiempo suscribió la Convención de las Naciones Unidas sobre los derechos de las personas con discapacidad y su protocolo facultativo ${ }^{3}$. En aquella ocasión, se comprometió a respetar la dignidad inherente

de 20 I 3 que prescribe la obligatoriedad del segundo nivel de transición y crea el sistema de financiamiento gratuito desde el nivel medio menor. Ley 20.835 de 20 I 5 que crea la Subsecretaría de Educación Parvularia y la Intendencia de Educación Parvularia. Ley 20.832 de 20I 5 que crea la autorización de funcionamiento de establecimientos de educación parvularia. Ley 20.845 de 20 I 5 sobre inclusión escolar y elimina el financiamiento compartido. Ratificación de los protocolos facultativos de la Convención sobre los derechos del niño relativos a la participación de niños en los conflictos armados (2003), a la venta de niños, a la prostitución infantil y la utilización de niños(as) en la pornografía (2003) y a la aprobación del protocolo facultativo relativo a comunicaciones directas (2015), entre otras.

$2 \quad$ El I 7 de junio de 20 I5, el Estado de Chile suscribió la Convención sobre Derechos Humanos de las personas mayores. Capítulo I, artículo I de la Convención. En ella se reconoce: "El respeto a la autonomía de la persona mayor en la toma de sus decisiones, así como a su independencia en la realización de sus actos". Artículo 7 de la Convención sobre derechos humanos de las personas mayores [en línea], AG, I 5, 20 I 5, disponible en http://www.ippdh.mercosur.int/wpcontent/uploads/20 I 5/o6/Espa-iol_convenci-ôn-interamericana-sobre-la-protecci-ôn-de-losderechos-humanos-de-las-personas-mayores.pdf [consultado 6 de mayo de 20r6]. En el mismo sentido, la Convención de La Haya sobre la protección internacional de los adultos (2000); los Principios de las Naciones Unidas en favor de las personas de edad (I99I); la Proclamación sobre el envejecimiento (I992); la Declaración política y el plan de Acción Internacional de Madrid sobre el envejecimiento (2002), así como los instrumentos regionales, tales como la Estrategia Regional de implementación para América Latina y el Caribe del plan de acción internacional de Madrid sobre el envejecimiento (2003); la Declaración de Brasilia (2007); el Plan de acción de la Organización Panamericana de la Salud sobre la salud de las personas mayores, incluido el envejecimiento activo y saludable (2009); la Declaración de compromiso de Puerto España (2009) y la Carta de San José sobre los derechos de las personas mayores de América Latina y el Caribe (2012).

3 El 25 de agosto de 2008 , el Estado de Chile se "comprometió a promover, proteger y asegurar el goce pleno y en condiciones de igualdad de todos los derechos humanos y libertades fundamentales por todas las personas con discapacidad y el respeto de su dignidad inherente. En ese empeño, deberá dar cumplimiento a los principios de vida independiente [...]". Artículos I y 3 de la Ley 20.422 , que establece normas sobre igualdad de oportunidades e inclusión social de personas con discapacidad. Las personas con discapacidad incluyen a aquellas que tengan deficiencias físicas, mentales, intelectuales o sensoriales a largo plazo que, al interactuar con 
a toda persona, la autonomía individual, incluida la libertad de tomar las propias decisiones, la independencia, participación e inclusión plena y efectiva en la sociedad de las personas con discapacidad. Tales convenciones complementan el ideal de sociedad basado en la persona, debido a que buscan reconocer y asegurar los derechos de la persona, en particular, el derecho a adoptar decisiones referentes a su vida privada, su salud, el destino de sus bienes y que dichas decisiones sean respetadas.

Sin embargo, al mismo tiempo que suscribió estas convenciones, mantiene únicamente un régimen general de incapacidad que no distingue entre incapacidad, discapacidad y dependencia de las personas en general, según se ha comenzado a reconocer, y que requiere como condición básica de operación la existencia de una voluntad incapaz de discernir con responsabilidad y con la debida independencia o libertad cuáles son los actos jurídicos que se desea realizar4. Bajo dicha premisa, la aplicación normativa supone, las más de las veces, la privación del uso, goce y disposición de los derechos por sus titulares, y desde ese momento el desplazamiento a un tercero de la decisión de cuándo y cómo va a hacer uso de tales atributos. Se advierte, de este modo, que la declaración

diversas barreras, puedan impedir su participación plena y efectiva en la sociedad, en igualdad de condiciones con las demás. Artículo i de la Convención de las Naciones Unidas sobre los derechos de las personas con discapacidad [en línea], Nueva York, I 3, 2006, disponible en https:// www.leychile.cl/Navegar?idNorma=2780 8 [consultado 23 de abril de 2016].

4 En nuestro país, durante el año 2014 ingresaron a los tribunales civiles 1326 solicitudes de interdicción por demencia, de ellas 676 terminaron con sentencia definitiva. En este mismo periodo, ingresaron solo i I causas de interdicción por disipación y 57I para nombrar curadores. INE-Chile. Justicia. Informe anual 20I4 [en línea], Santiago, 22, 20I 5, disponible en http:// www.ine.cl/canales/menu/publicaciones/calendario_de_publicaciones/pdf/justicia_20r4.pdf [consultado 2 de febrero de 2017]. En tanto que en el año 2015 ingresaron I 244 solicitudes de interdicción por demencia, de ellas 554 terminaron con sentencia definitiva. INE-Chile. Justicia. Informe anual 2015 [en línea], Santiago, 28, 20I6, disponible en http://www.ine.cl/canales/ menu/publicaciones/calendario_de_publicaciones/pdf/justicia_web. [consultado 2 de febrero de 2017 ]. El Tercer Juzgado de Letras de Iquique recurre de inaplicabilidad por inconstitucionalidad ante el Tribunal Constitucional, debido a que se ha solicitado la declaración de interdicción por demencia de una persona con discapacidad del treinta por ciento según procedimiento establecido en la Ley 19.284 y su Reglamento, situación que vulnera la CIDPD suscrita por el Estado de Chile. El Tribunal rechaza la declaración de inaplicabilidad de los artículos 456 del Código Civil y 4 de la Ley i 8.600, "por estimar que su aplicación en la causa aludida no produce resultados contrarios a la Constitución y porque una eventual adecuación de la legislación nacional a los parámetros derivados de la Convención de Naciones Unidas sobre los Derechos de las Personas con Discapacidad, vigente en Chile, debe ser efectuada por los órganos colegisladores, tal como se desprende del Mensaje de la Ley 20.422, de 2010, que, en la parte pertinente, indica: [...] el actual debate que se lleva a cabo en la Organización de las Naciones Unidas para la elaboración de una Convención Internacional Comprensiva e Integral sobre la Protección y Promoción de los Derechos y Dignidad de las Personas con Discapacidad, iniciativa apoyada por nuestro país desde sus inicios, nos plantea nuevos desafíos que demandan la adecuación de la legislación interna a las normas internacionales que en el futuro se aprueben en esta materia". Tribunal Constitucional, Rol 2703 de 26 de enero de 2016 [en línea], мPт, 26, 2016 (Historia de la Ley 20.422, Boletín 476-352), disponible en http://www.tribunalconstitucional.cl/wp/descargar_expediente.php?id=54466 [consultado I6 de febrero, 2017 ]. 
de incapacidad procede si el titular que tiene la aptitud para adquirir derechos y obligaciones carece de la voluntad que le permite ejercitar los derechos por él mismo o por un sujeto designado por él5. Se trata, en consecuencia, de una limitación a la capacidad de obrar, en virtud de la cual el ordenamiento establece que un tercero, designado por otro totalmente ajeno, debe obrar por tales personas.

Tal incapacidad de ejercicio podrá ser absoluta o relativa. Respecto de la primera, el ordenamiento señala que lo son, en esa medida, los dementes, los impúberes y los sordos o sordomudos que no pueden darse a entender claramente; estas personas no pueden ejecutar actos jurídicos de forma personal, sino solo representados; de lo contrario, dicho acto es nulo de nulidad absoluta ${ }^{6}$. En cambio, la segunda afecta a menores adultos y disipadores que se hallen bajo interdicción de administrar lo suyo, por lo que los actos ejecutados por estos sin estar autorizados o representados por quien corresponda adolecen de nulidad relativa.

Enseguida, una vez declarado interdicto, el incapaz requerirá para actuar en la vida del Derecho de una persona que vele por sus intereses y lo represente; si

5 Ramos Pazos, R., Derecho de Familia, 4. ${ }^{\text {a }}$ edición, Santiago, Editorial Jurídica de Chile, 2003, 592 y 593, y Barrientos Grandon, J., Código Civil, Santiago, Legal Publishing, 20 i 3, i io6. Domínguez Águila, R., Teoría general del negocio jurídico, 2. ${ }^{a}$ edición, Santiago, Editorial Jurídica de Chile, 20 I 2 , i 2.

6 El artículo I447 del Código Civil chileno señala quiénes son incapaces absolutos y relativos y los efectos de sus actos. Algunos tribunales, a su vez, señalan que para una mejor resolución y entendimiento del asunto sometido a la decisión "es preciso tener presente lo dispuesto en las normas que a continuación se señalan: [...] c) El artículo 342 del Código Civil, dice: 'Están sujetos a curaduría general los menores adultos; los que por prodigalidad o demencia han sido puesto en entredicho de administrar sus bienes; y los sordos o sordomudos que no pueden darse a entender claramente'; d) A su vez el artículo 456 del mismo cuerpo normativo señala: 'El adulto que se halla en un estado habitual de demencia, deberá ser privado de la administración de sus bienes, aunque tenga intervalos lúcidos'; e) Finalmente el artículo 465 del Código Civil, prescribe: 'Los actos y contratos del demente, posteriores al decreto de interdicción, serán nulos; aunque se alegue haberse ejecutado o celebrado en un intervalo lúcido"'. Corte de Apelaciones de San Miguel, causa 880/20r6 de 8 de agosto de 20i6, nulidad de contrato MMGF con JANR [en línea], vLex-646793 Io I, disponible en http://vlex.com/vid/guzman-fariasmiriam-navarro-646793 Ior [consultado el i de febrero de 20 i 7]. Corte de Apelaciones de Santiago, causa 8969/20 I 5 de I I de diciembre de 20 I 5, rehabilitación de la disipadora mecu con meus [en línea], vLex-64294934I, disponible en http://vlex.com/vid/cavallone-uribe-mariaeugenia-64294934I [consultado el I de febrero de 20I 7]. En el mismo sentido, Corte de Apelaciones de Valparaíso, causa 2559-2008 de 27 de enero de 2009 , interdicción por prodigalidad [en línea], vLex-5 I6507474, disponible en https://app.vlex.com/\#vid/5 I6507474 [consultado I de febrero de 20 I 7]. Corte de Apelaciones de Concepción, causa I 597/20 i I de 2 de diciembre de 20 I I, interdicción por prodigalidad [en línea], vLex-366592 Io6, disponible en http://vlex. $\mathrm{com} / \mathrm{vid} /-366592$ Io6 [consultado I de febrero de 2017]. Corte de Apelaciones de Coyhaique, causa $80 / 2015$ de 12 de diciembre de 2015 , interdicción por dilapidación de bienes JIMT con MEAA [en línea], vLex-642986085, disponible en http://vlex.com/vid/reyes-achurra-642986085 [consultado I de febrero de 20I7]. También, "La incapacidad absoluta o relativa son generales, porque abarcan, por regla general, todos los actos y contratos que puede ejecutar o celebrar el incapaz”. Alessandri Besa., A. Nulidad y Rescisión en el Derecho Civil chileno [en línea], Santiago, Ediar, I940, 472, disponible en http://www.bcn.cl/catalogo/detalle_libro?bib=32802 \&materia =Rescisión [consultado 3 de junio de 2015]. En el mismo sentido, Lyon Puelma, A., Personas naturales, $3 \cdot{ }^{\text {a }}$ edición, Santiago, Ediciones Universidad Católica de Chile, $2007,{ }_{72}$. 
no está sujeto a patria potestad o su incapacidad es otra, se designará una persona para que cumpla dicha función7. En tal nominación, interviene la ley llamando a las personas que podrán ejercer la curatela del hijo o el tribunal oyendo a los parientes del pupilo, para nombrar más de uno y dividir las funciones; mas nunca hasta ahora ha estado presente ni se ha considerado la posibilidad de que el incapacitado haya manifestado, siendo capaz, la persona que quiere que sea su curador.

Cierto es que la persona en el futuro no solamente puede necesitar que otro actúe por él o lo autorice para poder desarrollarse en las tareas de la vida diaria desde el punto de vista personal y patrimonial, sino también querer que tal persona sea designada por él mismo. Sin embargo, nuestro ordenamiento se limita a señalar las personas que han de ejercer la curatela; a contrario sensu, no faculta expresamente a la persona incapacitada, actualmente, para designar -mientras se encuentra en plenitud de sus facultades mentales, o bien de entendimiento- a otro que la sustituya o la represente cuando no sea capaz ${ }^{8}$.

Así, se advierte, en principio, que el sistema de protección (tutelas y curatelas) se caracteriza por comportar no solo una limitación de la capacidad de obrar de la persona, a través de un procedimiento judicial de incapacitación, sino que también, al parecer, no responde a los compromisos adquiridos en torno a garantizar la libertad de las personas para tomar sus propias decisiones en virtud de la autonomía de la voluntad antes y desde la incapacidad.

Tal crítica sirve de base, como ha ocurrido en el Derecho comparado, a la tarea de reformar las normas sobre capacidad, posibilitando medios de protección alternativos a la tutela y la curatela, centrados en la autonomía decisoria y la

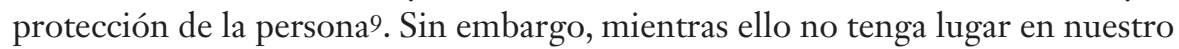

7 Se trata de "cargos impuestos a ciertas personas a favor de aquellos que no pueden dirigirse a sí mismos o administrar competentemente sus negocios, y que no se hallan bajo potestad de padre o madre, que pueda darles la protección debida". Artículo $33^{8}$ del Código Civil chileno.

8 Declarada la interdicción definitiva o provisoria del disipador, debe procederse a designársele un curador. Así lo dice el artículo 843 del Código de Procedimiento Civil. Por su parte, el Código Civil en su artículo 442 agrega: "[...] a los que por pródigos o disipadores han sido puestos en entredicho de administrar sus bienes, se dará curador legítimo, y a falta de éste, curador dativo". A su vez, el artículo 448, en concordancia con el artículo 29 de la Ley 7.613, señala las personas llamadas a la curaduría del disipador. A su turno, la ley preceptúa que, declarada la interdicción, se hace necesario nombrar un curador al demente, curaduría que podrá ser testamentaria, legítima o dativa (art. 456 inciso 2. ${ }^{\circ}$ del Código Civil). En todo caso, si no hay curador testamentario, se nombrará un curador legítimo que debe deferirse a las personas que señala el artículo 462 del Código Civil, complementado por el artículo 29 de la Ley 7.6r3.

9 La Convención de las Naciones Unidas, citada precedentemente, y la Recomendación del Consejo de Europa que establece los principios que se aplican a la protección de los adultos que, debido a una disminución o insuficiencia de sus facultades personales, no son capaces de tomar independientemente las decisiones con respecto a cuestiones que afectan a su persona o sus bienes establece los principios que han de informar la regulación de cada país, entre otros, el respeto de los derechos humanos (Principio i), Máxima conservación de la capacidad (Principio 3), Necesidad y subsidiariedad (Principio 5), Proporcionalidad (Principio 6), El respeto de los 
sistema, se debe dar desde el Derecho vigente una solución a todos quienes desean que su voluntad sea considerada cuando ya no puedan gobernar sus vidas y protegerse por sí mismos.

De ahí que esta investigación tiene por objetivo resolver si en nuestro sistema una persona capaz podría designar anticipadamente, en virtud de la autonomía de la voluntad, a otra que se hará cargo del cuidado de su persona y bienes, esto es, nombrar una persona -estando en condiciones físicas y mentales para hacerlo- para cuando ya no esté en situación de protegerse a sí misma, de modo que su familia no sea obligada a recurrir a procedimientos judiciales de incapacitación, cuya aplicación debiera pasar a ser subsidiaria y solo en situaciones en que sea necesario y, de ser posible, determinar cuál podría ser la figura jurídica idónea para que las personas mayores puedan expresar esta voluntad.

Las preguntas que orientan la conceptualización y delimitación del objeto de estudio de la investigación son: i) ¿Puede una persona capaz, mientras lo sea, designar a otra para que la represente cuando no pueda? ii) ¿Cuál es la figura jurídica apta para que las personas puedan expresar esta voluntad y cuáles son las dificultades que podrían suscitarse en la aplicación?

La metodología que se utilizará corresponde inicialmente al método comparado, debido a que en la primera parte de la investigación nos aproximaremos a la protección de la capacidad a través de la autonomía de la voluntad, tanto en la tradición romano-germánica, mediante el estudio de los ordenamientos francés, español y alemán, como en la del Common Law, por medio del Derecho inglés y de los Estados Unidos de América, porque en ellos se ha regulado, o bien reconocido, la protección por medio de la inclusión legislativa de la figura, o a través de contratos. En primer lugar, se describirán y sistematizarán las dificultades, tales como el momento desde el cual el mandato ha de desplegar sus efectos y la

deseos y sentimientos de la persona de que se trate (Principio 9); los deseos y sentimientos de la persona mayor deberían, siempre que sea posible, ser la base de las medidas adoptadas. Esto implica, en particular, la elección de una persona para representar y colaborar con él siempre que sea posible. Consejo de Europa, Recomendación 99 (4) del Comité de Ministros de los Estados miembros sobre los principios concernientes a la protección jurídica de los mayores incapaces (23 de febrero de r 999) [en línea], Reunión 660, 23, I999, disponible en http://www. discapnet.es/SiteCollectionDocuments/Discapnet/Documentos/DocTecnica/o409.html [consultado 24 de abril de 20i6]. De ahí que los ordenamientos inician el proceso de modificación de la regulación. En el Derecho francés, la Ley I $968-5$ de 3 enero de i 968 regula la salvaguardia de justicia, la tutela y la curatela y la Ley 2007-308 de 5 de marzo de 2007 modifica las instituciones anteriores e incorpora los mandatos de protección futura. El Derecho alemán a través de la ley de asistencia de I 2 de septiembre de 1990 y posteriormente la ley de 25 de junio de r 998 deroga la tutela e incorpora la asistencia Betreuung y los mandatos en caso de incapacidad futura Vorsorgevolmatcht. Posteriormente, por medio de swräG 2006 se refiere a los poderes de atención médica. El Derecho inglés por medio de Mental Capacity Act de 2005 consolida los poderes preventivos Lasting powers attorney y solo subsidiariamente corresponde el cuidado a la Court of Protection y finalmente el Derecho español a través de las leyes I $3 /$ I $_{9} 83$ de 24 de octubre de I 983,4 I/2003 de I 8 de noviembre de 2003 y I $5 / 20$ I 5 de 2 de julio de 20 I 5 modifica, radicalmente, el sistema tutelar que existía hasta ese momento. 
revocación. En segundo lugar, las facilidades de la protección a través de la autonomía de la voluntad, en particular, servir de instrumento de protección convencional de la persona, creando un régimen de representación especial sin afectar la capacidad del individuo. Luego, el examen de todos estos elementos permitirá dar una respuesta al problema de si puede una persona capaz, mientras lo sea, designar a otra para que la represente cuando no pueda tomar independientemente las decisiones con respecto a cuestiones que afectan a su persona o sus bienes.

\section{La protección de la capacidad en el Derecho comparado}

En el Derecho comparado la protección de la capacidad comprende en la actualidad una regulación muy variada en los distintos sistemas jurídicos que se han preocupado de la autonomía e independencia de las personas mayores. Sin embargo, hasta el día de hoy no puede afirmarse que existe acuerdo respecto del régimen más adecuado, como, por lo demás, tampoco respecto del contenido de este. En efecto, el estudio de las distintas familias jurídicas nos revela notables diferencias entre el estado actual de esta cuestión en los Derechos pertenecientes al Common Law y los que pertenecen a los Derechos de tradición romanogermánica $^{\mathrm{Io}}$. Es más, la variedad dentro de estos últimos es absoluta, de forma tal que podemos encontrar unos que para otorgar protección mantienen la figura de la interdicción, como consecuencia de la aplicación de las mismas reglas utilizadas para los menores; es el caso de Rumania ${ }^{\mathrm{II}}$. Otros, en cambio, contemplan una variada gama de modelos de protección, debido a que han adoptado el principio de reducir o eliminar cualquier limitación a la capacidad de obrar de las personas ${ }^{12}$.

Io Entre los ordenamientos que los admiten se encuentran: Inglaterra (I985), Escocia (I990) e Irlanda (i 996). Otros, por el contrario, rechazan tal solución expresamente. Así, por ejemplo, Bélgica, Italia y Suiza. En otros ordenamientos europeos, tal posibilidad no siempre está expresamente contemplada en la ley, aunque ello no quiere decir que no existe. En Alemania, por ejemplo, se admite la existencia de un Vorsorgevollmacht (apoderado en previsión de incapacidad), pero no se entiende necesaria una regulación concreta en el BGB porque los párrafos I68 у 672 del вGB permiten considerar tal previsión ya incluida en el supuesto de hecho. García V., E., La tutela de la propia incapacidad, México, Instituto de Investigaciones Jurídicas, unAM, 2007, 52 y $83-96$.

I I Codul familiei român (arts. I42 y siguientes) [en línea], Legea, actualizat, 20r6, disponible en http://www.dreptonline.ro/legislatie/codul_familiei.php [consultado 24 de abril de 20 I6].

I 2 Las leyes más recientes toman más en cuenta la voluntad de la persona protegida. Así queda de manifiesto en el Derecho francés y el alemán. En efecto, en ellos el libre albedrío del adulto puede intervenir en diferentes niveles, al permitirle que designe de antemano quién será el responsable de su protección, eventualmente a través de la solicitud de una medida de protección o de un mandato, en donde el adulto puede nominar o recomendar un tutor; oponerse a la designación de uno; limitar los poderes del tutor o curador o tomar decisiones sobre su salud o vida privada. Mas todo con el objeto de que el adulto siga siendo autónomo, según lo prevenido por la Recomendación del Consejo de Europa. Por su parte, en el Derecho francés, Loi 2007308 du 5 mars 2007 portant réforme de la protection juridique des majeurs, Titre xI, "De la 
En ese empeño han suprimido totalmente la expresión interdicción, tal es el caso de Alemania y Suecia, y han incorporado un sistema de protección flexible, esto es, capaz de adaptarse a la situación personal del afectado ${ }^{13}$.

majorité et des majeurs protégés par la loi", chapitre Ier, Section 2, "Des dispositions communes aux majeurs protégés", art. 4I 5-424 [en línea], disponible en http://www.legifrance.gouv.fr/ affichtextearticle.do;jsessionid $=53 \mathrm{~d}_{2} 245 \mathrm{f}_{2} 82357985506799 \mathrm{e} 300 \mathrm{e} 3$ [consultado 24 de abril de 20I6]. También en République Française, Direction de l'information légale et administrative [en línea], disponible en http://www.vie-publique.fr/actualite/panorama/texte-vote/loi-du5-mars-2007-portant-reforme-protection-juridique-majeurs [consultado 24 de abril de 2016]. Por último, Pellier, J. D., "Le mandat de protection future issu de la loi du 5 mars 2007 portant réforme de la protection des majeurs", en Les Petites Affiches, n. ${ }^{\circ} 83$, 2007, 4, y Cour des comptes La protection juridique des majeurs - septembre 20I6 Cour des comptes - www.ccomptes.fr - @ Courdescomptes [en línea], 28 y 30, disponible en https://www.ccomptes.fr/.../20I6roo4-rapport-protection-juridiqu. [consultada 22 de febrero de 2017]. En el Derecho alemán, Bürgerliches Gesetzbuch in der Fassung der Bekanntmachung vom 2. Januar 2002 (вGв. I S. 42, 2909; 2003 I S. 738), das zuletzt durch Artikel I des Gesetzes vom i . März 20 г6 (вяв. I S. 396), $\$ \$$ I 773 s., I 896 s., I 909 s. вGB) [en línea], disponible en https://www.gesetze-im-internet.de/bgb/ BJNROO I950896 [consultado 24 de abril de 2016]. También, Brauer, D., Autonomie und Familie: Bebandlungsentscheidungen bei geschäfts-und einwilligungsunfäbigen Volljäbrigen, Berlin, SpringerVerlag, 20I 3, IO3; FAUPEL, F., Die Betreuungsverfiigung. Ein Instrument zur privatautonomen Ausgestaltung der gesetzlichen Betreuung [en línea], Universitätsverlag Göttingen, 2010, 9, disponible en http://d-nb.info/ır $8668225 / 34$ [consultado 24 de abril de 20r6]. En cambio, en España, la Ley 4I/2003, de 18 de noviembre, de Protección Patrimonial de las personas con discapacidad, incorporó los poderes preventivos y la autotutela con la finalidad de potenciar la autonomía de la voluntad en la elección de quién y cómo se deben gestionar los propios asuntos para el caso de que uno ya no pueda hacerlo por sí mismo. Vid. Ley 4I/2003, de I 8 de noviembre, de Protección Patrimonial de las personas con discapacidad y de modificación del Código Civil, de la Ley de Enjuiciamiento Civil y de la Normativa Tributaria con esta finalidad [en línea], Exposición de Motivos (III), disponible en https://www.boe.es/diario_boe/txt.php?id=BOE-A-2003-2 IO53 [consultado 24 de abril de 2016].

I3 Los ordenamientos han definido la incapacidad de forma disímil. De hecho, en el Derecho alemán, la legislación se refiere tan solo a las causas de tutela y la asocia a la presencia de ciertos criterios, tales como la existencia de una enfermedad mental en los adultos (psychische Krankheit) o física, mental o emocional (körperliche, geistige oder seelische Behinderung) (cf. \$ I 896 párrafo I del вGв). En el Derecho francés, las leyes de 3 de enero de i 968 y de 5 de marzo de 2007 no definen expresamente el concepto de incapacidad. Sin embargo, las dos leyes en sus diversas disposiciones indican las características de las incapacidades y discapacidades. En la primera las causas correspondían, a saber: deterioro de las facultades mentales o físicas, la prodigalidad, la intemperancia y la ociosidad (arts. 488 y 5 I 4 del Código Civil francés). La segunda, en cambio, elimina las causas de prodigalidad, ociosidad e intemperancia y mantiene solamente el deterioro de las facultades mentales o físicas (arts. 4I4 y 5 I4 del Código Civil francés). El Derecho español señala que son causas de incapacidad las enfermedades o deficiencias persistentes de carácter físico o psíquico, que impidan a la persona gobernarse por sí misma (art. 200 del Código Civil español) y sustituye las expresiones incapaz e incapacitación por la referencia a las personas cuya capacidad está modificada judicialmente (Ley $\mathrm{I}_{5} / 2015$, de 2 de julio, de la Jurisdicción Voluntaria). Por último, en el ordenamiento inglés la capacidad se considera como un concepto funcional. No existe una lista exhaustiva, sino que la capacidad debe evaluarse sobre la base de si la persona puede tomar decisiones por sí misma, y para ello se considera, aunque no de forma determinante, la existencia de una enfermedad psíquica, una discapacidad de aprendizaje, demencia, daño cerebral, un estado de confusión provocado por intoxicación, la alteración de la conciencia... The Mental Capacity Act 2005, que entró en vigor el I de octubre de 2007, no contiene una lista exhaustiva de las causas de incapacidad. De acuerdo con The Mental Health Act 2007, de I9 de julio de 2007, varias causas pueden conducir a una discapacidad. La 
De ahí que en estos sistemas es posible distinguir las medidas de protección adoptadas por el tribunal u otra autoridad competente, de aquellas basadas en la autonomía de la voluntad, como, por ejemplo: Vorsorgevollmacht, Betreuungsverfügungen y Patientenverfügungen.

Respecto de los últimos, los sistemas no contienen, por regla general, un régimen especial que los regule. Así, por ejemplo, en el Derecho alemán tales mandatos están regulados en los párrafos I90 I y siguientes del вGB; sin embargo, no están sujetos a disposiciones específicas. El contenido de estas medidas puede consistir en la designación de un individuo por la persona para que se desempeñe como tutor en el futuro (Betreuungsverfügungen, órdenes de atención); respecto de la posibilidad de anticipar las decisiones sobre el tratamiento médico (Patientenverfügungen, "testamento vital"), o la designación de la persona y de los poderes que le permitirán hacerse cargo de la protección personal y patrimonial del incapaz, únicamente, en el caso de que no sea capaz de manejar todos o algunos de sus asuntos $(\$ 273$ ABGB AF O BZW $\$ 268$ Abs I ABGB) en un momento determinado (Vorsorgevollmacht, poderes de precaución) ${ }^{\mathrm{I} 4}$. A su turno, el Derecho francés contemplaba, junto a la tutela y la curatela, ciertas medidas de representación que incluyen la tutela total, administración legal bajo control judicial, en virtud de la gestión de tutela y custodia delimitada. No obstante, en 2007 el legislador incorporó las medidas de protección jurídica, algunas de naturaleza judicial y otras basadas en la autonomía de la voluntad, entre estas últimas el mandato de protección futura ${ }^{15}$. Se trata de una figura de carácter

ley establece diferentes grados de discapacidad [en línea], All legislation, 2005, disponible en http://www.legislation.gov.uk/ukpga/2005/9/contents [consultado 2 de febrero de 2017 ] y [en línea], All legislation, 2007, disponible en http://www.legislation.gov.uk/ukpga/2007/r 2/contents [consultado 7 de mayo de 20I6], respectivamente. También en Dimond, B., Legal aspects of mental capacity, Great Britain, Blackewell Publishing, 2008, 34.

I4 Ein Sachwalter kann nur bestellt werden, wenn eine Person aufgrund einer psychischen Krankheit oder geistigen Behinderung nicht in der Lage ist, alle oder einzelne ibrer Angelegenheiten obne die Gefahr eines Nachteils fiur sich selbst zu besorgen (vgl $\$ 273$ ABGB aF bzw $\$ 268$ Abs I ABGB). Eine rein körperliche. Schopper, A., Patientenverfüigung und vorsorgevollmacht. das österreichische patientenverfiugungs- und sachwalterrechts-änderungsgesetz 2006, USA y uK, Südwestdeutscher Verlag für Hochschulschriften, 2008, i70. En el mismo sentido, Hack, J., Buecking, B., Lopez, C. L., Ruchнoltz, S., Kühne, C. A., "Patientenverfügung, Vorsorgevollmacht und gesetzliche Betreuung im unfallchirurgischen Alltag Zahlen aus einem alterstraumatologischen Zentrum", Zeitschrift für Gerontologie und Geriatrie, vol. 49, n. ${ }^{\circ}$ 8, 20 I6, 72 I. También, Нack, J., Buecking, B., López, S., Ruchnoltz, C. L., KüHne, C. A., "Vorausverfügungenimklinischen Alltag Patientenverfügung, Vorsorgevollmacht und Betreuungsverfügung", DerUnfallchirurg, n. ${ }^{\circ}$ 2, 2017 , I 55 y I 56 . Wever, C., "Patientenverfügung, Vorsorgevollmacht und Sterbehilfe", MedR, n. ${ }^{\circ}$ 29, 20 I I, I 30 . Vorsorgevollmachten, und betreuungsverfügungen, Druck: Hausdruckerei, Bremen, 2008, 7, 8 y го, disponible en http://www.jobcenter-bremerhaven.de/downloads/256/1336r/ Broschuere_Vorsorgevollmacht.pdf [consultado 22 de febrero de 2017].

I5 Article 477. Modifié par ordonnance 20I5-I288 du I5 octobre 2015 - art. I3. "Toute personne majeure ou mineure émancipée ne faisant pas l'objet d'une mesure de tutelle ou d'une habilitation familiale peut charger une ou plusieurs personnes, par un même mandat, de la représenter pour le cas où, pour l'une des causes prévues à l'article 425 , elle ne pourrait plus pourvoir seule à 
contractual que "permite a una persona con capacidad suficiente organizar su propia protección para un momento futuro en que no esté en condiciones de formar y expresar su voluntad"`6. Por último, el Derecho español mediante la reforma 4I/2003 se alinea en la órbita de otros ordenamientos que, aunque con diferencias, reconocen la subsistencia del mandato o el poder conferido para la gestión de cuestiones relativas al patrimonio una vez declarada la incapacidad/ incapacitación del otorgante, si este lo ha previsto expresamente ${ }^{17}$.

En cambio, en aquellos ordenamientos pertenecientes al Common Law, por ejemplo el Derecho inglés, se mantiene, junto al guardianship (tutela) y la receivership (administración judicial), una figura contractual a través de la cual se confiere representación. Primeramente, mediante The Mental Capacity Act de I985 se incorporaron los enduring powers of attorney que permitían establecer mandatos de representación voluntaria limitados a la herencia, aunque fueron derogados por The Mental Capacity Act de 2005. De modo que los nuevos poderes de representación quedan sujetos a ella -aunque se mantiene vigente respecto de aquellos suscritos con anterioridad-. Actualmente, The Mental Ca-

ses intérêts. La personne en curatelle ne peut conclure un mandat de protection future qu'avec l'assistance de son curateur. [...]".

i6 Peтerka, Nathalie, "Le mandat de protection future: bilan et perspectives", Defrénois, 2017 , n. ${ }^{\circ}$ 8., 497-505. Cheval, Christopher y Hannecart, Weyth, "Mandat de protection future. Personnes vulnérables: e`est maintenant”, Droit \& patrimoine, 20I4, n. ${ }^{\circ} 238,33$ (total 32-37). Gatti, Laurence, "L'exemple du mandataire de protection future", en Remy, Benjamin, Le mandate en question, Buexelles, Bruylant 2013, 4r. Boyer, P., "Le mandat de protection future", Revue Française de Comptabilité, n. ${ }^{\circ}$ 445, 20 I I, I 2. Fossier, T., "Protection du majeur vulnérable", en Murat, P. (director), Droit de la famille, París, Dalloz, 2008/2009, iooz. Ladsous, J., "Les notaires, la loi du 5 mars 2007 et le mandat de protection future", Vie sociale, n. ${ }^{\circ}$ 3, 2010, 6r. Fenouillet, Dominique, "Le mandat de protection future ou la double illusion", Repertoire au notariat, n. $^{\circ}$ 2, 2009, I 42-I 77. Meimon, C., "Le mandat de protection future", Reliance, n. ${ }^{\circ} 28$, 2008, i i 8. Delfose, Alain y Baillon, Nathalie, La réforme du droit des majeurs protégés, París, Litec, 2009, I 7 I y I 72. Probate Notice d'information du mandat de protection future sous seing prive (article 492 du Code civil). Ministere de la Justice, Le mandat de protection future ne peut pendre effet que s'il est etabli que le mandant ne peut plus pourvoir seul a ses interêst [en línea], $\mathrm{n}^{\circ}{ }_{5}$ I $226 \mathrm{O}_{\mathrm{O} 2}$, disponible en http://www.udaf ${ }_{2}$. fr/sites/default/files/public/docs/espacetuteurs-familiaux/notice_infos_mandat_protect [consultado 24 de abril de 2016].

I7 El mandato se acaba: r. ${ }^{\circ}$ Por su revocación. 2. ${ }^{\circ}$ Por renuncia o incapacitación del mandatario. $3{ }^{\circ}$ Por muerte, declaración de prodigalidad o por concurso o insolvencia del mandante o del mandatario. El mandato se extinguirá también por la incapacitación sobrevenida del mandante a no ser que en el mismo se hubiera dispuesto su continuación o el mandato se hubiera dado para el caso de incapacidad del mandante apreciada conforme a lo dispuesto por este. En estos casos, el mandato podrá terminar por resolución judicial dictada al constituirse el organismo tutelar o posteriormente a instancia del tutor. Artículo I 732 del Código Civil español. PéREZ DE VARGAS, J., "Las reformas del derecho español en materia de autotutela y de poderes preventivos", en Pérez de Vargas, J. (director), La Encrucijada de la incapacidad y la discapacidad, Madrid, La Ley, 20 I I, 95. También, De Amunátegui, C., Incapacitación y mandato, Madrid, La Ley, 2008, I83, y en "Los poderes preventivos en el Derecho español: luces y sombras", en PÉREZ DE VARGAS J. (director), La encrucijada de la incapacitación y la discapacidad, Madrid, La Ley, $20 \mathrm{I}$, 266 y 267 . Gallego, I., "Consideraciones sobre el mandato de protección futura en el Derecho francés. Su regulación”, en Pérez de VARgas, J. (director), La encrucijada de la incapacitación y la discapacidad, Madrid, La Ley, 201 I, 292. 
pacity Act de 2005 prevé dos posibilidades: en primer lugar, la posibilidad de que el mandante nombre un tutor general para que actúe en su nombre ante una posible pérdida de capacidad en el futuro y, en segundo lugar, la posibilidad de un representante nombrado por el tribunal. Del mismo modo, en la legislación de los Estados Unidos convive la designación del Tribunal junto a la posibilidad de que la persona pueda suscribir mandatos particulares, tales como enduring powers of attorney, para que se haga cargo de ella cuando ya no sea capaz, o bien tome decisiones puntuales en el caso de someterse a un tratamiento médico ${ }^{18}$.

Ahora bien, respecto a las dificultades que derivan de su naturaleza jurídica y eficacia, se suele señalar que la protección de los incapaces mediante la normativa de los contratos, independientemente de las instituciones protectoras, dificulta la función tuitiva que el Derecho debe tener ante las situaciones de incapacidad. En ese sentido, uno de los problemas más recurrentes -antes de las reformas- consiste en la pérdida de capacidad del mandante como causa de eficacia de la figura y que, una vez que el mandato produzca efectos, no podrá ser revocado por el mandante. Pero, además, surge la cuestión sobre la determinación del momento a partir del cual es eficaz, en concreto, desde la incapacidad del mandante o desde la pérdida de la capacidad de obrar ${ }^{19}$.

La respuesta de los sistemas jurídicos frente a tales cuestionamientos ha sido que se trataría de una normativa contractual, de un régimen de protección de la persona que, precisamente por ser privado y sin control judicial en su desarrollo, se regula por las normas que se refieren a los contratos; es el caso del Derecho alemán, en particular, que constituye un mandato sui generis, por cuanto adquiere vigencia a partir de la incapacitación del mandante; otros más generales le atribuyen el carácter de un negocio unilateral recepticio, en el Derecho español, y,

I 8 Dimond, B., Legal aspects of mental capacity, Great Britain, Blackwell Publishing, 2008, 84. MARTINs, R. "The importance of a Lasting Power of Attorney", Quality in ageing and older adults, vol. I 4, n. ${ }_{3}^{3}, 2013,2$ I 8. Lund, S., "Lasting power of attorney: a significant ethical responsibility", British fournal of Hospital Medicine, vol. 76, n. ${ }^{\circ}$ 9, 201 5, 5 I 8 y 5 I 9. Conroy, A. J., "Curbing the license to steal: a discussion of english law and possible reforms for the durable power of attorney" [en línea], Real Property, Trust, and Estate Law fournal, 44 (I), 2009, 3 I, disponible en https://search.proquest.com/docview/208 I63793 ?accountid=I4478 [consultado Io de febrero de 20I7]. Decedent's mental incapacity tolled claims, rules Tennessee Supreme Court [en línea], Boston, May 2 I, 2007: Sullivan v. Chattanooga Medical Investors, LP (Lawyers usA n. ${ }^{\circ}$ 9935740), Tennessee Supreme Court n. ${ }^{\circ}$ o2-5088C-II, April 24, 2007, disponible en http:// search.proquest.com/docview/2 I I I 72772 ? pq-origsite=summon [consultado io de febrero de $2017]$.

I9 “[...] se alegan tres razones: en primer lugar, escapan totalmente al control judicial; en segundo lugar, dejan al poderdante incapaz totalmente desprotegido frente a terceros ya que, a pesar del poder, podrá concluir negocios jurídicos perjudiciales cuya validez se va a presumir, y en tercero, impiden la impugnación a posteriori de los actos realizados por el representante, alegando la incapacidad del representado". CALlejo, C. "La representación voluntaria del incapaz", Revista Crítica de Derecho Inmobiliario, n. ${ }^{\circ} 7$ I I, 2009, I I. También, De Amunátegui, C., "Los poderes preventivos en el Derecho español: luces y sombras", en Pérez de VArgas J. (director), La encrucijada de la incapacitación y la discapacidad, Madrid, La Ley, 20 I I, 253 y 275. 
finalmente, quienes dicen que participa a la vez de la naturaleza del contrato y de la institución de la protección, por ejemplo, en el Derecho francés ${ }^{20}$.

De otra parte, respecto a la pérdida de capacidad del mandante como causa de ineficacia, el tema no ha sido pacífico debido a que después de afirmarse categóricamente que la pérdida de la capacidad o incapacitación extingue el mandato fundado en el hecho de que el mandatario no puede hacer aquello para lo que no está capacitado el mandante, y por ende, una vez que haya disminuido sus aptitudes no solamente quedaría el mandatario sin legitimación para actuar, sino también reemplazada la representación voluntaria por la legal ${ }^{21}$. Ha surgido la postura contraria que estima que en esta situación debe primar la capacidad de las personas de contraer y asumir derechos y obligaciones protegidas por la ley a partir de la expresión de su libre voluntad, mediando un objeto lícito, una causa legítima y un consentimiento expreso para obligarse en dicho acto de libre disposición; en otras palabras, habiendo conformidad con la ley, es posible contratar. Todavía más, sostiene que en estas circunstancias el mandante otorga el poder estando en plena capacidad para poder realizar personalmente el o los negocios que confía al mandatario, y la circunstancia de que después pierda su capacidad inicial no establece la extinción del poder de representación, debido a que la regla general en el ordenamiento jurídico es la capacidad, lo que refrenda la actuación del mandatario, pues el poder subsiste mientras no se declare la incapacitación o pierda la capacidad, aunque la persona no la posea, fundamentalmente en sus relaciones con terceros, espacio en el que despliega los efectos el poder de representación de acuerdo con la distinción entre el mandato y la representación ${ }^{22}$. De este modo, se han podido regular derechos de contenido no patrimonial, esto es, derechos que son parte de la personalidad.

20 En el Derecho alemán, el poder está regulado en el párrafo §igorc que hace mención a la figura y que en todo lo no dispuesto por aquella se regula por el Derecho de los contratos. En el Derecho español, la figura está regulada en el artículo I 732 del Código Civil que se refiere al mandato. En el Derecho francés, la figura está contemplada en el artículo 477 del Code, requiere aceptación del mandatario y ante la omisión actúan supletoriamente las normas contenidas en los artículos i 840 a 20 io que se refieren al contrato de mandato.

2 I Muñız, E., "La incapacidad y las reformas del derecho contractual", Derecho Privado y Constitución, n. ${ }^{\circ}$ 23, 2009, 294. Pereña Vicente, M., Dependencia e incapacidad. Libertad de elección del cuidador o del tutor [en línea], Madrid, Universitaria Ramón Areces, 2008, 85 y 88, disponible en http://vlex.com/vid/capitulo-iii-poderes-preventivos-22 82 I046 I [consultado 26 de enero de $2017]$.

22 López, JuAn, "Autonomía de la voluntad, poder público y orden constitucional”, en Autonomía de la voluntad en el derecho privado (coordinador Prats, Lorenzo), España, Wolters Kluwer, 20I 2 , 8, Linacero, M., Tratado de Derecho de Familia, Valencia, Tirant lo Blanch, 20 i6, 453. Díez-Pi-

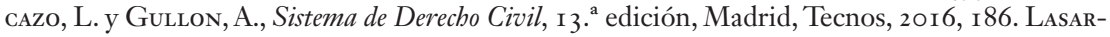
TE, C., Curso de Derecho Civil patrimonial. Introducción al Derecho, 22. a edición, Madrid, Tecnos, 20i6, i69 y 326. Cano Martínez de Velasco, J., "El apoderamiento y el poder representativo" [en línea], vlex-277654, disponible en http://vlex.com/vid/apoderamiento-poder-representativo-2 77654 [consultado 30 de enero de 20 I 7]. GaLindo, I., "Representación, mandato y poder", Revista de Derecho Privado, año I, n. ${ }^{\circ}$ I, 2002 , I 5. 
En consecuencia, se ha concluido que, mientras el mandante no haya sido incapacitado judicialmente o se demuestre que ha perdido la capacidad, el poder o el mandato continúan produciendo sus efectos ${ }^{23}$.

Así, respecto del momento desde el cual el poder ha de desplegar sus efectos, se distingue: si se ha dispuesto que el poder continúe a pesar de la incapacidad sobrevenida del poderdante, el poder despliega sus efectos desde el momento del otorgamiento. Por tanto, si el poderdante no hace esta previsión, se extinguirá por esta causa. Si el poder se ha otorgado para el caso de incapacidad sobrevenida del poderdante, hasta que no tenga lugar ese hecho, no será eficaz el poder.

En lo que dice relación con la revocación, en los ordenamientos pertenecientes a la familia romano-germánica se ha señalado que en efecto la revocación es una forma de extinción del mandato que se concibe en interés del propio mandante que ya no desea continuar con el contrato. Sin embargo, en los mandatos de protección futura o poderes preventivos la situación es la inversa: "es el mandante quien desea que el mandato continúe en aras de su propia protección cuando -en realidad- de seguirse las reglas generales debería extinguirse; de modo que ha de atenderse a la voluntad del mandante" ${ }^{24}$. De ahí que se deja la posibilidad de revocar el mandato mientras este no haya comenzado a producir efectos, o al juez de intervenir poniéndole fin para evitar los abusos del mandatario para cuando el mandante ya no pueda hacerlo ${ }^{25}$. Confiriendo, así, la

23 La mandante ha dispuesto que para que el poder conserve su eficacia debe estar muerta o incapacitada. olg Karlsruhe Beschluß vom I4.9.20I 5, I I Wx 7I/I 5 [en línea], Justiz BadenWürttemberg, disponible en http://lrbw.juris.de/cgi-bin/laender_rechtsprechung/document. py?Gericht=bw\&nr=198I 2 [consultado I6 de febrero de 20I7]. El Tribunal concluye que la persona sufre de una discapacidad mental, a saber, una demencia moderada relacionada con la edad, con la pérdida de todas las habilidades esenciales. Mediante el auto recurrido, el Tribunal de Distrito rechazó la designación del supervisor de la persona en cuestión. LG Verden·Beschluss vom 2. Januar 20I3 Az. I T I 77/I 2 [en línea], Entscheidungsdatenbank Niedersachsen, disponible en http://www.rechtsprechung.niedersachsen.de/jportal/bsndprod.psmldoc.id=KORE5047 $72013 \& s t=n u l l \& s h o w d o c c a s e$ I [consultado i6 de febrero de 2016].

24 De Amunátegui, C., Incapacitación y mandato, Madrid, La Ley, 2008, i88. En el mismo sentido, De Verda y Beamonte, J., "Estudio de la extinción del mandato desde un punto de vista jurisprudencial", Actualidad furídica Iberoamericana, n. ${ }^{\circ}$ 2, 201 5, 523 y 53 I. CANo MARTínez DE Velasco, J., "Soluciones que se proponen" [en línea], vlex-277657, disponible en http://vlex. $\mathrm{com} / \mathrm{vid} /$ soluciones-proponen-2 77657 [consultado 30 de enero de 2017].

25 El Tribunal revoca mandato entregado al hijo y otorga su cuidado a una institución de protección. Cass. civ. Ière, I2/OI/20II, n. ${ }^{\circ}$ o9-16.5 I9 [en línea], Mandat de protection future curatelle, disponible en www.leparticulier.fr/.../mandat-de-protection-future [consultado 9 de mayo de 20r6]. El Tribunal pone término al mandato y somete al mandante a tutela protegida. Cour de cassation civile, Chambre civile I, 29 mai 20I3, I2-19.85, disponible en https://www. legifrance.gouv.fr/affichJuriJudi.do?oldAction=rechJuriJudi\&idTexte [consultado 9 de mayo de 20r6]. El Tribunal de Apelación de Douai ha hecho una fuerte crítica a la posición de la Corte de Apelación de París sobre la aplicación del principio de subsidiariedad en presencia de un mandato de protección futura. Le ha recordado que el mandato de protección futura es una de las grandes novedades de la ley de 5 de marzo de 2007. Es un contrato que permite a cada uno de nosotros establecer de antemano las consecuencias de nuestra propia vulnerabilidad y nuestra incapacidad futura y que debe aplicarse prioritariamente [en línea], Courd'Appel de Douai 3, I 2 
posibilidad de revocar siempre el mandato, salvo que a través de la voluntad se haya establecido expresamente el carácter de irrevocable ${ }^{26}$; sin embargo, no es necesario que la revocación se tome en cuenta; los negocios concluidos por el mandatario, a pesar de la revocación, son válidos ${ }^{27}$, fundado en que su actuación debe estar bajo control, sobre todo porque de lo que se trata es de proteger al mandante contra su incapacidad de revocar una vez que sobreviene la incapacidad. Tan solo se discrepa sobre qué tipo de control habría que establecer y por quién. Aunque, en esto, algunos optan por dar prioridad a la voluntad del mandante que podría, por ejemplo, incluir una cláusula en el mandato en la que designara las medidas; también subsidiariamente la ley establece controles ${ }^{28} \mathrm{y}$,

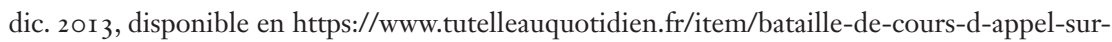
l-execution-d-un-mandat-de-protection-future [consultado 9 de mayo de 2016]. El Tribunal revoca el poder conferido a los dos sobrinos por utilizar los fondos en su beneficio. The Public Guardian v MD, wD, The London Borough of Brent Case n. ${ }^{\circ}$ I 2452930 , Court of Protection, [20I4] EWCOP I 2 20I4 WL 367I639 [en línea], 7 July, 20I4, disponible en http://login.westlaw. co.uk/maf/wluk/app/document? \&srguid=ioad 82 do80oooo I 5 a 45 fe 88 fc 2 bf I b4 Io \& docguid=id 4

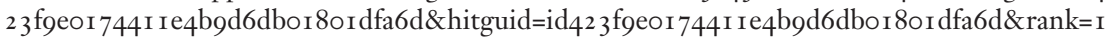
\& spos $=\mathrm{I} \&$ epos $=\mathrm{I} \& \mathrm{td}=4000 \&$ crumb-action $=$ append $\&$ context $=\mathrm{I} 9$ \& resolvein=true [consultado I6 de febrero de 2016]. El Tribunal decide dejar sin efecto el poder debido a las continuas desavenencias entre los hijos, situación que perjudica la buena administración. Court of Protection: [2004] EWHC 725 (Ch); [2004] 3 All E.R. 277; [2004] W.T.L.R. 657; (2004) IOI(I 7) L.s.G. 3 I [en línea], 29 April, 2004, disponible en http://login.westlaw.co.uk/maf/wluk/app/search/run?a $\mathrm{o}=$ \&ndd=\&sttype =stdtemplate\&srguid $=$ \& context= I \& crumb-action=append \& crumb-label=Se arch+Results\&sortid=order-by-elementrelevance\&noiclr=false \&frt=power+of + attorney\&butt onsearch=buscar\&ds2=uk-cases-all\&searchtype=fulltext. La Corte desestima el recurso que intenta dejar sin efecto el poder debido a que la mandante no era capaz en el momento de otorgarlo. Court of Appeal: [200I] Ch. 609; [200I] 2 W.L.R. 957; [200I] 4 All E.R. 88; [200I] I F.L.R. 832; [2003] 3 F.C.R. 663; [200I] Fam. Law 262; (200I) 98(4) L.s.g. 50; (200I) I45 S.J.L.B. I6 [en línea], January Iо, 200I, disponible en http://login.westlaw.co.uk/maf/wluk/app/document? \&srguid

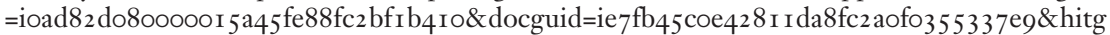
uid $=$ ie 7 fb 45 coe 428 I I da8fc 2 aofo 355337 e 9 \&rank=4\&spos $=4 \&$ epos $=4 \&$ td $=4000 \&$ crumb-actio $\mathrm{n}=$ append \& context= I 9 \& resolvein=true [consultado I 6 de febrero de $20 \mathrm{I} 7$ ]. El tribunal desea repatriar a una persona mayor que se encuentra en Portugal, sin embargo la persona había concedido poder preventivo en Portugal. Court of Appeal: [2017] ewca civ 34 [en línea], 30 January, 2017 disponible en ogin.westlaw.co.uk/maf/wluk/app/document? \&srguid=ioad8289e ooooo I 5 a 46 I adf 263 c4f6 5 d 7 \&docguid=i3 I 36 fbeoe 79 I I I e6bdbdbed 2 eeg9ea 8d \& hitguid=i3 I 36

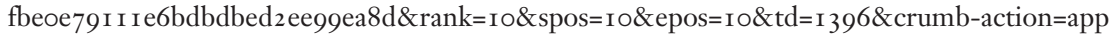
end \& context=39\&resolvein=true [consultado I 6 de febrero de 2017 ].

26 Vid. \$ I 76, III del вGB en relación con los artículos 626 y 723 de la citada norma legal. Morón Kavanagh, M., "La representación en el Derecho Civil argentino y en el Derecho Civil alemán”, Revista del Notariado, n. ${ }^{\circ} 892,2007$, I4I.

27 Vid. artículo 483 del Code Civil, \$ I 908 в вв del Derecho alemán y los artículos I 732 y I 733 del Código Civil español.

28 El Código Civil francés contempla en el artículo 484 que cualquier persona interesada puede recurrir al juez de tutela con el fin de impugnar la ejecución del mandato o pedirle que decida sobre los términos y condiciones de su ejecución. Por su parte, el Derecho español concibe en la Ley de Enjuiciamiento Civil -artículo 762- la adopción, por parte del juez, de las medidas de protección de la persona o bienes del presunto incapaz que estime necesarias, pudiendo actuar de oficio, requerido por el Ministerio Fiscal, o a instancia de parte. 
como mínimo, se considera el deber de realizar inventario si el mandato comprende la administración y siempre rendir cuenta ${ }^{29}$.

Por último, en cuanto a desde qué momento se precisa incapaz el mandante, la regla ha sido desde que ya no puede atender por sí mismo sus intereses, debido a que sus facultades mentales o corporales se encuentran afectadas, de modo tal que le impiden expresar su voluntad. Así, en algunos ordenamientos esto queda sujeto a la libre apreciación del mandante, en tanto en otros se establece un procedimiento que consta de la entrega del mandato y de la certificación médica de parte de ciertos profesionales enlistados que dan cuenta del estado del presunto incapaz, a veces sin y en otros con la intervención del juez de tutela ${ }^{30}$.

En el Derecho alemán, por ejemplo, el mandato se basa en la confianza personal, de manera que se extingue con la pérdida de la capacidad de obrar del mandante, salvo disposición contraria. En este caso, el mandato y, por consiguiente, el poder subsiste hasta que el mandante esté en condiciones de proveer de otra manera, el heredero y el representante legal del mandatario están obligados y autorizados a concluir los negocios que sean necesarios en este lapso ${ }^{3 \mathrm{I}}$. En cambio, en el Derecho francés, dispone el Código que ello acontece cuando el mandante no pueda proteger por sí mismo sus intereses, circunstancia que será notificada por el tribunal al mandante $3^{2}$.

Asimismo, en los ordenamientos pertenecientes al Common Law, el mandato de representación voluntaria es siempre revocable por la persona protegida, aunque puede ser rechazada por el representante. En efecto, el mandato de representación voluntaria, de acuerdo con The Mental Act de 2005, puede ser revocado en cualquier momento, siempre que la persona recupere su capacidad para tomar decisiones. Del mismo modo, el mandato de representación limitado a la herencia, según la ley de $1985^{[33]}$.

En el Common Law, el mandato produce efectos desde que se manifiesta la incapacidad, de modo que no existe la necesidad de recurrir al tribunal para que

29 La solución en el Derecho alemán ha sido admitir la posibilidad de nombrar un asistente controlador del mandatario uberwachungsbetrever (1893, 3 BGB), dependiente del Tribunal de tutelas, aunque, como sustituto, la doctrina también admite la posibilidad de un doble apoderamiento (doppelbevollmachtigung, con el fin de que ambos mandatarios tengan que actuar por unanimidad). En el Derecho francés el mandatario debe hacer inventario y rendir cuenta (artículos 503 y 5 ro del Código Civil francés).

30 Artículo r 732 del Código Civil español, artículo 43 I del Code Civil y i 90 I del вGB.

3 I En el Derecho alemán, \$ 673 con relación al г3 I del вGв. En el Derecho español, la Ley 4I/2003 de I 8 de noviembre modificó el artículo I 732 del Código Civil en términos de que actualmente señala: "El mandato se extinguirá también, por la incapacitación sobrevenida del mandante, a no ser que en el mismo se hubiera dispuesto su continuación o el mandato se hubiera dado para el caso de incapacidad del mandante apreciado conforme a lo dispuesto por éste $[\ldots] "$.

32 Artículo 48 I del Código Civil francés. Fossier, T. "Protection du majeur vulnérable", en MuRAT, P. (director), Droit de la famille, París, Dalloz, 2008/2009, IOI 3.

33 Mental Capacity Act 2005, sección I3 (2), anexo 4. 
designe a un tutor; las expresiones de voluntad del mandante priman por sobre cualquier otra consideración legal en el momento de establecer quién será la persona que lo protegerá cuando no pueda gobernar su vida34.

En tanto, una vez que la reforma ha tenido lugar, los inconvenientes -en algunos ordenamientos- se han situado en la forma, la inscripción, el contenido de los poderes y las obligaciones y responsabilidad del mandatario, así como un control sobre su actuación, no obstante la participación del notario en la constitución y del Registro en la inscripción. Tal situación ha venido a poner de manifiesto la relación que existe entre la autonomía de la voluntad y la limitación que impone la seguridad jurídica desde la perspectiva del derecho notarial y registral, debido a que los efectos de la constitución no se limitan al poderdante, sino que irradian a terceras partes. Dicha situación ha traído consigo la necesidad de recurrir a la autoridad judicial para alterar la voluntad del mandante 35 .

Tal es el caso del ordenamiento jurídico español, debido a que la normativa española no logró armonizar la posibilidad de autorregulación de las relaciones jurídicas particulares basadas en el principio de la autonomía de la voluntad con la seguridad. En ese sentido, se ha hecho notar la ausencia de garantías en la ejecución del mandato. Los mandatos han quedado sujetos a los resguardos que adopten las partes, de modo que el único control consiste en recurrir al juez para que proceda a la incapacitación y deje sin efecto el poder. Luego, no se ha exigido como solemnidad la escritura pública, de modo que no ha sido posible contar con la colaboración del notario en la acreditación de capacidad, disminuir las futuras demandas de nulidad y por sobre todo fijar la fecha exacta en la que se inicia el mandato.

34 Mental Capacity Act 2006, sección I3 (2 y 6). Institut suisse de droit comparé, Lausanne, "Etude Comparative sur le régimes juridiques de protection des majeurs incapables" [en línea], 2008, 45. Disponible en www.europrl.europa.eu/activities [consultado el 3 de mayo de 20r6].

35 Los tribunales han decidido imponer el respeto a la voluntad manifestada por una persona que, en previsión de una situación de incapacidad, designa en escritura pública aquella o aquellas personas que deben ejercer la tutela para el supuesto de producirse dicha situación. Audiencia Provincial de Barcelona, 20/07/2016 n. ${ }^{\circ}$ de Recurso: r288/201 5, n. ${ }^{\circ}$ de Resolución: 609/20r6. Recurso de Apelación SAP в 7730/2016 - ECLI: ES: APB:20r6: 7730. En el mismo sentido, se respeta la voluntad de la recurrente y se la declara parcialmente incapaz. Audiencia Provincial de Barcelona, 2 I/o7/201 5 n. ${ }^{\circ}$ de Recurso: 3 I I/201 5, n. ${ }^{\circ}$ de resolución: $567 / 2015$, Recurso de Apelación. SAP в 6813/201 5 - ECLI: ES: APB: 2015:681 3 . También, Audiencia Provincial de Barcelona de o6/o7/20i6, n. ${ }^{\circ}$ de Recurso: 26r/20i6, n. ${ }^{\circ}$ de Resolución: 549/20r6. Recurso de Apelación. SAP в 7646/20I6 - ECLI: ES: APB:20I6: 7646. Lo mismo tiene lugar en Audiencia Provincial de Barcelona de 09/04/2015, n. ${ }^{\circ}$ de Recurso: 916/20I4, n. ${ }^{\circ}$ de Resolución: 234/2015, Recurso de Apelación. SAP B 3743/201 5 - ECLI: Es: APB:2015: 3743. En ocasiones, niegan el ejercicio de la tutela debido al desarrollo de una administración en contra de los intereses del incapaz. Tribunal Supremo. Sala de lo Civil de Madrid de o3/o6/2016, n. ${ }^{\circ}$ de Recurso: $2367 / 2015$. STS 2573/20i6 - eCLI: es:Ts:20i6: 2573. Por último, véase Tribunal Supremo. Sala de lo Civil, Madrid, I9/1 I/2015, n. ${ }^{\circ}$ de Recurso: 62/2015, n. ${ }^{\circ}$ de Resolución: 635/2015. Casación sts 47II/2OI 5 - ECLI: ES:TS: 20I 5:47I. 
En cambio, en otros ordenamientos, la constitución está rodeada de formalidades. Por ejemplo, el Derecho francés regula dos tipos de mandato, uno notarial y otro privado. El primero debe constar en escritura pública y contiene facultades amplias respecto de la persona y bienes del mandante. El segundo requiere de aceptación y la intervención de un abogado. Además del hecho de que debe consignarse en documentos oficiales ${ }^{36}$.

Enseguida el Derecho inglés exige que la constitución de los lasting powers attorney se lleve a cabo por el Public Guardian con el objeto de que se registre el momento en que deben quedar cumplidas las formalidades que establece la Mental Capacity Act.

Respecto de las facultades y poderes del mandatario, se ha recurrido a la figura del mandato, debido a que el código no las menciona expresamente. En tanto, al igual que la situación anterior, en otros ordenamientos, como el francés, el mandatario por medio del mandato notarial podrá efectuar, por sí mismo, todos los actos respecto de los cuales el tutor necesita autorización judicial 37.

Lo mismo ocurre en el Derecho inglés, las facultades del mandatario se extienden a actos personales y patrimoniales del mandante, incluso a título gratuito, de acuerdo con lo dispuesto en la Mental Capacity Act.

Por último, en cuanto al control, este está sujeto a lo establecido por las partes y en subsidio a lo dispuesto por el Código civil respecto del mandato. Siendo que en ordenamientos como el francés, la función de control la desempeña el juez a través de la integración o bien la alteración de contenido del mandato. Del mismo modo, el derecho inglés dispone primeramente del control del Public Guardian y posteriormente de la Court of Protection por medio de la alteración e interpretación del poder $3^{3}$.

Con todo, igualmente se ha considerado que para resguardar la capacidad no hace falta respetar irrestrictamente la tipicidad de la figura contractual, más cuando la realidad social ha ido por delante de la función legislativa y ha sido ella la que ha permitido conjugar la realidad jurídica con la social ${ }^{39}$.

36 Cour de cassation civile, Chambre civile I, 4 janvier 2017, I5-28. 669, Publié au bulletin [en línea], disponible en https://www.legifrance.gouv.fr/affichJuriJudi.do?idTexte [consultado 25 de julio de 20I7]. También, Cour de Cassation, 20 I I, Avis n. ${ }^{\circ}$ oroooo en línea], disponible en http//courdecassation.fr/jurisprudence_2/avis_classes_date234/20II_3825/2O_ juin20 I I_I I00004-3988/capitaine_cl_conseiller_2 I 093 html. [consultado 25 de julo de 20I 7].

37 Noguéro, David, "Priorité du mandat de protection future et réflexion sur sa publicité, son bomologation, sa validité et sa révocation» (IDS - UMR- INSERM I I45) [en línea] 20I4, 9, disponible en http:// www.davidnoguero.com/wp-content/uploads/20 I6/o I/Mandat-de-protection-future.-Cassjanvier-20r 7.pdf [consultado 25 de julio de 20i6.]. También, Сombret, Jacques, Las "personnes vulnérables", Madrid, Colección Scientia Iuridica, 20 го, 88-91.

38 De Amunátegui, Cristina, "Los poderes preventivos: un apunte sobre su reciente regulación en los códigos civiles español y francés, en Familia y discapacidad (coordinadora Diaz, SiLvia), Madrid, Colección Scientia Iuridica, $2010,47-49$.

39 Figueroa, Marta, Autonomía de la voluntad, Puerto Rico, Dykinson, 20 i6, i i 8-i i 9. 


\section{Estado de la cuestión en el Derecho chileno}

En el Derecho chileno, la doctrina nacional no ha abordado el tema de la protección de la capacidad por medio de la autonomía de la voluntad. Hasta ahora, ha resaltado que en nuestro país no se ha avanzado en la protección de las personas como sujetos de derecho y se ha concluido que nuestra legislación, desde la capacidad, es sumamente limitada y poco respetuosa de sus derechos individuales, dadas las reglas que regulan la demencia, como criterio de protección de la persona y fomento de su capacidad disminuida. También, ha examinado la situación jurídica de los adultos mayores en Chile y analizado la discriminación por edad y propuesto algunas soluciones legales para protegerlos. Enseguida, frente al problema puntual de cómo incapacitar a una persona que sufre un trastorno de dependencia de sustancias, en especial de la cocaína, admite que la "legislación chilena no provee un régimen especial para la interdicción de esas personas, por lo que es necesario determinar si deben aplicarse las reglas propias de la interdicción por demencia o por prodigalidad para lograr una protección de estas personas y un resguardo para sus cónyuges y parientes". Por último, solamente Ruz se refiere a esta posibilidad a propósito del análisis que realiza de la reforma del Derecho francés. De ahí que sostiene que "en ese sistema las personas por medio del mandato pueden válidamente anticipar las consecuencias de una futura incapacitación facultándola, con pleno respeto de su autonomía y voluntad individual, para organizar las medidas de protección de su persona y bienes para cuando ya no pueda protegerse a sí misma" 40 .

Tampoco lo ha hecho la jurisprudencia. Sin embargo, a través del conocimiento de causas relacionadas con solicitudes de nulidad de actos celebrados por una de las partes en supuesto estado de demencia, o bien porque el curador no ha querido obedecer la voluntad del incapaz, ha advertido la complejidad que supone respetar la libertad de las personas para decidir por medio de la autonomía de la voluntad lo que convenga a su persona y bienes de acuerdo a que la capacidad es la regla general y que la decisión producirá efectos jurídicos, no obstante se haya perdido, posteriormente ${ }^{4}$. Ello ha llevado a pronunciarse sobre

40 Barcia Lehmann, R., "Algunas críticas al derecho común y especialmente a la regulación de las incapacidades respecto del adulto mayor en el ordenamiento jurídico chileno", Revista Chilena de Derecho Privado, n. ${ }^{2}$ 23, 2014, 57-86. Lathrop, F., "Protección jurídica de los adultos mayores en Chile", Revista Chilena de Derecho, vol. 36, n. ${ }^{\circ}$ I, 2009, 77-I I 3. Corral Talciani, H., "Interdicción de personas que sufren trastorno de dependencia a la cocaína”, Revista de Derecho, vol. xxIv, n. ${ }^{\circ}$ 2, 20 I I, 3 I-64. Ruz, G., El Mandato: ensayos doctrinarios y comentarios de furisprudencia, Santiago, Thomson Reuters, 2013,5 .

4I En este sentido, la jurisprudencia ha señalado que en nuestro sistema jurídico "la voluntad preside y determina la extensión, los efectos y duración de los contratos, lo que significa que, [...], será el acuerdo de voluntades de las partes el que rija los diversos vínculos que se crean y sus alcances; [...], normando particularmente la relación jurídica que crean, desde sus respectivas posiciones, sea en un ámbito previsto y reglamentado específicamente por el legislador o no". Corte Suprema, causa 2 I 79/20 Io de 26 de agosto de 20 i I [en línea], vLex-333763 I 22, disponi- 
la incapacidad declarada del mandante como causal de terminación del mandato y también respecto de la eficacia de la gestión de negocios encargada al mandatario, no obstante haberse iniciado un juicio de interdicción por demencia, que resulta con sentencia que la declara ${ }^{42}$.

En tanto, el legislador se ha limitado a derogar la Ley i 8.600 del año I 987 y reemplazarla por la Ley 19.954 de 2004 que establece un procedimiento de tipo no contencioso para declarar la interdicción de una persona en estado de demencia, y designarle un curador que se encargue no solo de su cuidado personal, sino también de la administración de su patrimonio. Sin embargo, contradictoriamente, ha mantenido la Ley 20.286 de 2008 que modificó el numeral I 7 del art. $6 .^{\circ}$ de la Ley i 9.968 sobre el procedimiento aplicable para declarar la interdicción, esto es, un juicio ordinario contencioso, por aplicación del artículo 3 del Código de Procedimiento Civil. De modo que hoy se discute cuál es el procedimiento a seguir e incluso se solicita iniciar un procedimiento judicial contencioso, no obstante haber tramitado uno no contencioso.

Actualmente, abocado a tramitar dos proyectos de ley: uno que dispone la autodesignación de curador en previsión de una futura discapacidad en los siguientes términos: "Toda persona en previsión de una incapacidad futura podrá autodesignarse mediante escritura pública a una o más personas mayores de edad como sus curadores generales para tomar las decisiones sobre actos que le conciernan, en caso de hallarse privadas del discernimiento necesario". "En dicho acto, podría también disponer directivas anticipadas sobre su persona, bienes y salud, así como designar curadores sustitutos", basado en la necesidad de incorporar una nueva forma de generar la institución de la curaduría, reconociendo la fuerza de voluntad de la persona que se autodesigna un curador en

ble en http://vlex.com/vid/-333763I 22 [consultado 29 de enero de 2017]. Corte de Apelaciones de Santiago, causa I2957/20I5 de I 5 de junio de 20I6, comodato precario, JLMC con XGRB [en línea], vLex-647775929, disponible en http://vlex.com/vid/saldivia-carrasco-gustavo-maldonado-647775929 [consultado I de febrero de 20I7]. Corte Suprema, causa 23968/20I6 de 27 de octubre de 20I6, nulidad, RHvм con м del cvm [en línea], vLex-65207798 I, disponible en http://vlex.com/vid/vera-miranda-ruperto-vera-65207798I [consultado I de febrero de 20I7].

Corte Suprema, causa 9232/20I4 de I 2 de noviembre de 20I4, Indemnización de perjuicios por responsabilidad contractual, POG у AOR con моR (confirmada) [en línea], vLex-5435788 I4, disponible en http://vlex.com/vid/olivares-elizondo-miguel-angel-5435788I4 [consultado 29 de enero de 2017]. Corte Suprema, causa 2 I79/2010 de 26 de agosto de 20 I I, nulidad de contrato de donación, GD, SD con Arzobispado de Santiago y PC (rechazada) [en línea], vlex333763 I22, disponible en http://vlex.com/vid/-333763I22 [consultado 29 de enero de 2017 ]. Corte Suprema, causa $8485 / 2013$ de 15 de septiembre de 2014, nulidad de contrato de cesión de derechos (rechazada) [en línea], vLex-528284278, disponible en http://vlex.com/vid/moranalegria-lautaro-zamorano-elba-528284278 [consultado I de febrero de 2017]. Corte Suprema, causa I5572/20I 5 de 22 de marzo de 2016 , nulidad, MP, J con MP, CG y otro (acogida casación fondo, anula sentencia de Cortes de Apelación: 766-20 5 y de r ${ }^{\text {er Juzgado de Letras de Quillo- }}$ ta que daban lugar a la nulidad de los actos) [en línea], vLex-63158638 I, disponible en http:// vlex.com/vid/medina-pichara-jaime-medina-63 I 58638 I [consultado I de febrero de 20I 7 ]. 
previsión de una incapacidad futura 43 ; otro, que se encuentra en primer trámite constitucional y que deroga los numerales $\mathrm{I} .^{\circ}$ y $2 .^{\circ}$ del artículo 497 del Código Civil, relativos a la incapacidad de ciegos y mudos para desempeñar toda clase de tutelas o curatelas 44 .

Todo lo anterior permite concluir que el sistema chileno ha examinado apenas la posibilidad de proteger la capacidad a través de la autonomía de la voluntad como alternativa a la incapacitación de la persona e institución prioritaria a la curatela.

\section{El mandato como medio para proteger la capacidad de las personas}

En ese sentido, se ha considerado, entre otras razones, que el reconocimiento y el respeto a la persona, ante todo, a su dignidad, conlleva permitirle, mientras sea capaz, hacerse cargo de su vida, conducirse por sí misma, asumiendo su facultad de autodeterminación, para elegir y decidir sobre sus acciones y medios para llevarla a cabo 45 . En virtud de esa consideración, no es sino la propia persona la indicada para decidir atendiendo a sus propios intereses sobre quién quiere que conduzca su vida cuando ya no pueda hacerlo.

También, porque en aquellas situaciones, como en estas, en donde de plano no existen normas que resuelvan el asunto, se plantea la cuestión sobre el disenso relativo a si la solución debe buscarse solo en lo permitido expresamente o prohibido por el Derecho ${ }^{4}$. De acuerdo con el concepto de Derecho que se

43 Artículo 353 bis en el Código Civil. Boletín 6282-07 de I 7 de diciembre de 2008 que establece la autodesignación de curador en previsión de una futura discapacidad y que se encuentra en primer trámite constitucional; primer informe de comisión de Constitución, Legislación y Justicia.

44 Artículo 497 numerales I. ${ }^{\circ}$ y $2 .^{\circ}$ del Código Civil. Boletín 9.409-07 que deroga numerales I. ${ }^{\circ}$ y $2 .^{\circ}$ del art. 497 del Código Civil relativos a la incapacidad de ciegos y mudos, para desempeñar toda clase de tutelas o curatelas que se encuentren en segundo trámite constitucional; primer informe de comisión de Constitución, Legislación y Justicia.

45 Es la autonomía preventiva y consustancial "que se manifiesta en el respeto de la voluntad de la persona que es quien decide el sistema o modelo que hay que poner en marcha si llega a perder la capacidad y elige la persona que realizará las funciones de apoyo o representación [...]” y "que se manifiesta en el espacio de decisión, relacionado con cuestiones personales y derechos de la personalidad, que conserva la persona protegida a pesar de la puesta en marcha de un sistema de apoyos o representación que tiene que respetar su capacidad natural, sus deseos y su voluntad", respectivamente. Pereña, M., "Autonomía y voluntad en la dependencia y la incapacidad" [en línea], fornadas Dincat, Barcelona, 2010, 2, disponible en http://www.dincat.cat/autonomia-ivoluntat-en-la-depend $\% \mathrm{C}_{3} \%$ A8ncia-i-la-incapacitat_57I 84 [consultado 8 de mayo de 20I6]. En el mismo sentido, Mєј́́, R., Estipulaciones de autotutela para la propia incapacidad: la penúltima voluntad, Lima, Grijley, 2009, I44.

46 "Son de orden público las reglas que fijan el estado y capacidad de las personas". León, A., $L a$ voluntad y la capacidad en los actos jurídicos, Santiago, Editorial Jurídica de Chile, I952, 47. Claro Solar, L., Explicaciones del derecho civil chileno y comparado, vol. II, Santiago, Editorial Jurídica de Chile, i992, 50. Alessandri Rodríguez, A.; Somarriva Undurraga, M.; Vodanovic H., A., 
posea y que expresa una determinada concepción de la naturaleza y esencia de este, es posible concebirlo como un sistema cerrado de normas y a la norma como la única fuente posible de Derecho47. De ser así, en estos casos, no podría sino aplicarse las reglas de capacidad que conforman el ordenamiento jurídico chileno. En tanto, por otra, si se conciben los principios junto a las reglas como parte esencial del derecho, la respuesta en los casos en que no exista norma que los resuelva, provendría del hecho de encontrar un principio jurídico de donde derivar la solución al problema ${ }^{4}$. Luego, frente al problema de admitir si las personas puedan designar quién los represente cuando ya no sean capaces, la respuesta pasará por resolver la paradoja entre el principio de legalidad y, a la vez, realizar los valores de la autonomía y la libre determinación, incorporada por los derechos humanos, y en particular por los tratados suscritos por el Estado de Chile en esta materia, probablemente a favor de estos últimos 49 .

Además, los inconvenientes de un proceso de incapacitación, que -aunque la ley dispone que el disipador como el demente no verán restringida su libertad personal, debido a que, el primero, “[...] conservará siempre su libertad"; en cuanto al segundo, la regla general es que no será privado de su libertad personal, salvo "en los casos en que sea de temer que usando de ella se dañe a sí mismo, o cause peligro o notable incomodidad a otros" $50^{\circ}$ - no gradúa la incapacidad del

Tratado de Derecho Civil: Partes Preliminar y General, Santiago, Editorial Jurídica de Chile, I998, 47. "Tribunal Constitucional, Io de febrero de I995", en Revista de Derecho y Furisprudencia y Gaceta de los Tribunales, t. xII, Santiago, Editorial Jurídica de Chile, 42.

47 Hart, H. L. A., The Concept of Law, Oxford University Press, I96 I, I 5 I y I 53; Hart, H. L. A., The Concept of Law, $2^{\text {nd }}$ edition, Clarendon Press-Oxford, I99I, Ioo y I55; Kelsen, H., Teoría pura del derecho: Introducción a la ciencia del derecho, 2. ${ }^{a}$ edición, México, Universidad Nacional de México, I982, I5. Kelsen, H., Teoría pura del derecho: Introducción a la ciencia del derecho, $4{ }^{a}{ }^{\mathrm{a}}$ edición, Buenos Aires, Eudeba, r99i, 45 y 53.

48 Dworkin, R., El imperio de la justicia, 2. ${ }^{a}$ edición, Barcelona, Gedisa, I992, 78. Rojas, V., El concepto de derecho de Ronald Dworkin [en línea], Biblioteca Virtual de Investigaciones Jurídicas de la UNAM, 2006, 376, disponible en http://www.juridicas.unam.mx/publica/librev/rev/facdermx/ cont/.../arti6 [consultado 23 de abril de 20r6]. Ramos, J. A., "Positivismo jurídico y derechos humanos", en Pérez Bermejo, J. M. y Rodilla González, M.Á. (eds.), Jurisdicción, interpretación y sistema jurídico [en línea], Salamanca, Universidad de Salamanca, 2007, i I 9 y I 20, disponible en https://books.google.cl/books?isbn $=8478003789$ [consultado 23 de abril de 2016].

49 "La integridad es burlada no sólo en compromisos específicos de ese tipo sino cada vez que una comunidad aprueba y hace cumplir distintas leyes cada una de las cuales es coherente en sí misma, pero no pueden ser defendidas en conjunto como la expresión de una serie coherente de diferentes principios de justicia, de equidad o de debido proceso". Dworkin, R., El imperio de la justicia, 2. ${ }^{a}$ edición, Barcelona, Gedisa, I992, I27. Vid. "Normas, principios y directrices políticas", en Dworkin, R., Los derechos en serio, Barcelona, Editorial Ariel, 20I2, 72 y 79.

Artículos 453 inciso r. ${ }^{\circ}$ y 466 inciso r. ${ }^{\circ}$ del Código Civil chileno. Todavía más, prevé que, por regla general, el disipador tendrá disponible, para sus gastos personales, una suma de dinero, proporcionada a sus facultades, y señalada por el juez, que puede administrar con independencia del curador. Solamente "en casos extremos" el juez puede autorizar al curador negarle esta independencia y proveer él mismo a la subsistencia del disipador, procurándole los objetos necesarios. Esto no ocurre con el demente. Así también lo señalan autores como Ramos, R., Derecho de Familia, 5. ${ }^{a}$ edición actualizada, Santiago, Editorial Jurídica de Chile, 2005, 605 y 
incapacitado y se ciñe a la situación patrimonial y no a la situación personal de aquel. En otras palabras, la sentencia que declara la incapacitación no determina la extensión y los límites de esta. Como se ha dicho, lo único que persigue es constatar las carencias que tiene esa persona, articulando los mecanismos legalmente previstos para suplir o completar esa falta de capacidad; omite que el incapaz pueda, en lo posible, ejercitar sus derechos, de los que seguirá siendo titular, en condiciones de igualdad respecto a los demás ciudadanos ${ }^{5}$. De modo que, al parecer, no permite tal libertad.

Todavía más, esto ha dado lugar, según se acaba de comprobar a través de la experiencia jurisprudencial, a que en los hechos se incurre en la práctica insegura de conferir poderes generales que se intenta impugnar probando su ineficacia; la inclusión de esta posibilidad margina el uso, y consagra una alternativa firme y eficaz de lo realizado por el apoderado una vez que el poderdante ha perdido la capacidad.

También, el cada vez más común desinterés familiar por ejercer el cuidado de la persona motiva la protección de la capacidad a través de una vía contractual que puede llevarse a cabo por cualquier persona, incluso en ejercicio de su profesión, que goce de su confianza $5^{2}$.

siguientes. Lyon Puelma, A., Personas naturales, 3 . $^{\text {a }}$ edición, Santiago, Ediciones Universidad Católica de Chile, 2007, I 79.

5 I "La interdicción es el proceso mediante el cual se declara judicialmente la incapacidad absoluta o relativa de una persona mayor de edad para el ejercicio de sus derechos. El Código Civil establece que esta declaración de incapacidad sólo puede realizarse en razón de la existencia de una deficiencia intelectual, mental o de otro tipo que afecte la capacidad de una persona para tomar decisiones. La declaración se realiza a través de un proceso sumarísimo y, en la práctica, sin defensa legal, en el cual el juez determina sobre la base de una pericia médica que la persona requiere un curador para su rehabilitación y protección. Determinada la incapacidad, el juez restringirá de manera absoluta el ejercicio de todos los derechos de la persona interdicta, incluyendo derechos tales como votar, contratar o contraer matrimonio. Más aún, debido a que el sistema no promueve la rehabilitación de la persona ni la revisión de las sentencias, ser declarado interdicto supone en la práctica la muerte civil de una persona". VÁsquez EnCALADA, A., "El fin de la interdicción civil, la reforma de la que nadie está hablando" [en línea], Revista Ideele, n. $^{\circ}$ 250, disponible en http://www.revistaideele.com/ideele/content [consultado I de mayo de 20i6]. Grimaldi de Caldera, E. y Bilbao de Romero, G., "El enfermo mental en nuestro ordenamiento jurídico", Revista de la Facultad de Derecho de la Universidad de Carabo$b o, 45-85$. En el mismo sentido, vid. GonzÁlez, O., "¿Tiene sentido la incapacitación de los enfermos mentales?", Revista de la Asociación Española de Neuropsiquiatría, vol. 26, n. ${ }^{\circ}$ 2, 2006, 4i r. Recover, T., "Hacia la reforma del Código Civil y la Ley de Enjuiciamiento Civil en materia de discapacidad" (director García Garnica, M. del C.), Nuevas perspectivas del tratamiento jurídico de la discapacidad y la dependencia, Madrid, Dykinson, 2014, 25. Domínguez, A., Derecho Sanitario y responsabilidad médica, 2. ${ }^{\mathrm{a}}$ edición, Valladolid, Lex Nova, 2007, 239. Noticias jurídicas [en línea], 27, 08, 2015, disponible en http://noticias.juridicas.com/conocimiento/articulosdoctrinales/ro439-la-incapacitacion:-nuevo-enfoque-jurisprudencial-de-la-proteccion-depersonas-con-discapacidad [consultado 8 de mayo de 20r6].

52 Díez-Picazo, Luis y Gullón, Antonio, Sistema de Derecho Civil iv, 9. ${ }^{a}$ edición, Madrid, Tecnos, 2004,8 . 
Finalmente, y por sobre todo la autonomía de la voluntad, comprendida como la facultad del individuo para decidir sobre los asuntos que atañen a su persona y manifestar esas decisiones por vía de las opciones que ejerce al conducirse de una manera u otra en los distintos ámbitos del diario vivir 53 . En ese contexto, el ordenamiento jurídico reconoce la autonomía de las personas para que, haciendo uso de la libertad, establezcan las relaciones jurídicas que les parezcan más oportunas y las regulen conforme a las normas que ellos mismos establezcan quien los va a cuidar, sin perjuicio de los límites internos y externos que en la contratación se deben cuidar54.

Así, se reconoce y ampara el poder de autodeterminación de la persona, siempre y cuando dicha expresión de disposición no exceda los límites predispuestos por el marco legal. De modo tal que existe un espacio de autonomía individual limitado por la desigualdad de los contratantes y por la acción del Estado por medio del legislador y el aparato jurisdiccional. Se trata, en primer lugar, de los límites establecidos por la ley en términos de imponer o prohibir ciertos contenidos, fundados en la intención de proteger el interés general. En segundo lugar, el respeto de la moral, las buenas costumbres y el orden público. Finalmente, el poder de la judicatura para integrar y modificar la manifestación de voluntad 55 .

Es más, si se considera que esta manifestación de voluntad -destinada a designar a quien va cuidar de la persona y de sus bienes- está dentro del ámbito del Derecho de Familia, pues bien, el principio de la autonomía de la voluntad en esta parte del derecho está limitado por la Constitución, la igualdad, la protección de la familia, los hijos y la seguridad jurídica ${ }^{6}$.

53 Barcia, Rodrigo, "La autonomía privada como principio sustentador de la teoría del contrato y su aplicación en Chile”, Cuadernos de Análisis furídico, n. ${ }^{\circ}$ III, 2006, 72.

54 Figueroa, Marta, Autonomía de la voluntad, capitulaciones matrimoniales y pacto en previsión de ruptura, Madrid, Dykinson, 2016, 92. Soro, Olivier, El principio de la autonomía de la voluntad privada en la contratación: génesis y contenido actual, Madrid, Reus, 20i6, 57. Barrio, Aurelio, Autonomía privada y matrimonio, Madrid, Reus, 20 6 , 6 y 8.

55 Lasarte, Carlos, Curso de Derecho Civil patrimonial, 22. . edición, Madrid, Tecnos, 20i6, 289. Díez -Picazo, Luis y Gullón, Antonio, Sistema de Derecho Civil, Madrid, Tecnos, 2oi6, 3IO-3I3.

56 Lepin, Cristian, Los nuevos principios del Derecho de Familia, Revista Chilena de Derecho Privado, $2014, n^{\circ}{ }_{2} 3,44$. Veloso, Paulina, "Nuevos principios del derecho de familia en función, principalmente, de la normativa internacional que emana de los tratados de derechos humanos", Revista de Derecho de la Universidad Católica de Valparaíso, n. xix, I 998, 55. Verdugo, Ismael, "La relación entre la autonomía privada y los contratos atípicos”, Revista Ars Boni et Aequi, n. ${ }^{\circ}$ 4, 2008, IO4 [en línea], disponible en http://www.ubo.cl/icsyc/wp-content/uploads/201 I/o9/7Verdugo.pdf [consultado 26 de julio de 20I7]. IsLer, ERIKA, "Los principios en la ley I 9.947: análisis y desarrollo", Revista Ars Boni et Aequi, n. ${ }^{\circ}$, 2009, 98 [en línea], disponible en https:// dialnet.unirioja.es/descarga/articulo/3257724.pdf [consultada 26 de julio de 2017 ]. 
En consecuencia, se puede afirmar que no existe razón o limitación que impida exteriorizar la voluntad a través de un acto que persigue reglamentar de forma autónoma una relación jurídica como la descrita.

Desde esa mirada, "el mandato" se presenta como una solución, por un lado, porque constituye un encargo de confianza, el mandante confía al mandatario la gestión de uno o más negocios. Por eso, el encargo es un acto intuito personae, tanto desde el punto de vista del mandante como del mandatario. Por otro, mediante el mandato se podría encargar la realización de actos jurídicos, o bien que se lleve a cabo cualesquiera negocios ajenos, entendidos en sentido amplio como una actividad económica, aunque esta no suponga la realización de actos jurídicos 57 . Esta segunda posición supone al mandato como un encargo que consiste en manejar negocios, esto es, realizar los actos conducentes para cuidar de un cierto interés patrimonial. De este modo, es posible encargar a otro la administración de un patrimonio, "aun en lo que esta gestión tenga de puramente material (en oposición a jurídico) [...]" ${ }^{8}$. Todavía más, también es posible que el mandato se otorgue para celebrar actos de familia.

Con todo, el mandato puede incluir actividades económicas, que se materializan en la realización de actos jurídicos y materiales en interés del mandante. En suma, el concepto de negocio que recoge el Código Civil chileno es amplio y permite la realización de una serie de actividades en interés del mandante.

De ahí que la gestión podría ir más allá del cuidado de los negocios del mandante, pues podría incluir también el cuidado de la persona de este; por consiguiente, permitiría confiar el cuidado de la persona y bienes del propio mandante para cuando este ya no pueda autoprotegerse; por último, permitiría asumir la función de servir de instrumento de protección convencional de la persona, creando un régimen de representación especial sin afectar la capacidad del individuo. No obstante las dificultades que -en principio- podría tener desde el punto de vista de la naturaleza jurídica y de la eficacia a partir de las causales de terminación, en particular, la revocación y la interdicción del mandante, debido a que dejaría al mandante sin esa facultad y no podría producir efecto, sino una vez declarada la interdicción, y luego que empiece a producirlos, el mandante incapaz no podría revocarlo59.

En virtud de tales consideraciones se plantea primeramente que, de ser el mandato la figura idónea, debiera considerarse frente a tales reproches que el

El mandato es general si se da para todos los negocios del mandante. Vid. Art. 2 I 30 del Código Civil chileno.

58 Del Mandato, Título xxix, artículos 2 I I 6 y siguientes del Código Civil chileno. STITchKin, D., "El Mandato Civil", Revista de Derecho de la Universidad de Concepción, n. ${ }^{\circ}$ 47, XII, I994, 25 O-2 74. Strтchкin, D., El Mandato Civil, $5 \cdot{ }^{a}$ edición actualizada por Gonzalo Figueroa Yáñez, Santiago, Editorial Jurídica de Chile, 2009, 534. Henríquez, I., El mandato. Ensayos doctrinarios y comentarios de jurisprudencia, Santiago, Editorial Thomson Reuters, 2013, 236.

Artículo 2 I 63 del Código Civil chileno. 
sistema chileno distingue entre mandato y representación en términos tales que el mandatario puede actuar a nombre propio, o bien en representación del mandante; en cambio, el apoderado tiene una sola forma de actuar, esto es, en ejercicio del poder de representación del poderdante ${ }^{60}$. El mandato es un contrato que puede constituir fuente de la representación, el poder de representación no es un contrato, es solamente un acto unilateral del poderdante que consiste en atribuir una competencia al apoderado para que pueda actuar en representación de él, sin que este último, en principio, adquiera obligación alguna.

Se sigue de lo anterior que, en el evento de que se trate de un mandato sin representación, los actos ejecutados por el mandatario seguirán siendo por cuenta y riesgo del mandante, no obstante la inexistencia de una relación contractual entre ambos, y que, eventualmente, pueda ser considerado acreedor de los gastos de la gestión útil si la actuación ha resultado beneficiosa al mandante, si se considera como un agente oficioso ${ }^{61}$. Esto significa que, igualmente, se obliga para con él, y lo obliga en ciertos $\operatorname{casos}^{62}$.

En suma, si el mandante ha otorgado mandato siendo capaz para que produzca efectos una vez que se ha tornado incapaz, aun cuando se estime que el mandato es rescindible por nulidad relativa, mientras ello no sea sentenciado por el tribunal el mandato será eficaz, ya sea por sí mismo y como tal o porque ha degenerado en una figura distinta, cuasicontractual, que a este tenor obliga al mandatario y al mandante en ciertas situaciones, según se acaba de señalar.

En segundo lugar, respecto a la eficacia, se suele señalar que al ser el mandato intuito personae y generalmente un contrato de tracto sucesivo sin plazo de terminación, este puede terminar por revocación, como por hechos sobrevinientes no voluntarios, entre ellos, la interdicción del mandante. En ese sentido, si bien la regla general es que el mandante puede revocar a su arbitrio, lo que ha llevado a plantear por algunos que se trata de un elemento de la esencia y no natural porque en derecho "no es admisible que una persona quede ligada en una

60 Artículo 2 15 I del Código Civil chileno.

6I Por su parte, los autores han señalado que "[...] el mandatario, al ejecutar el encargo que se le confía, puede o no actuar en representación del mandante, pero en uno y otro caso, subsiste el mandato, con una diferencia importante: si actúa a nombre propio, no hay duda que es el consentimiento o voluntad del mandatario y no el del mandante el requerido. Pero incluso si el mandatario, en la ejecución del encargo, no actúa en representación del mandante sino a nombre propio, siempre será el mandante quien reciba los beneficios y soporte las pérdidas [...], y ello es así, porque el mandato subsiste, no puede desconocerse por el mandante ni por el mandatario". Meza Barros, R., Manual de Derecho Civil. De las fuentes de las obligaciones, tomo I, 8. a edición, Santiago, Editorial Jurídica de Chile, r995, 358. También, Orrego, J., "El Mandato" [en línea], ro enero, 2017,6 , disponible en https//73705fd 5 odada36d.jimcontent.com/download/.../Contrato\% 2ode\% 20Mandato.pdp.3 [consultado r6 de febrero de 20I7], y FigueroA, G., El Patrimonio, Santiago, Editorial Jurídica de Chile, I991, I 57. Vid. El artículo 2289 del C. C.

62 Artículos 2 I 22 y 2286 del Código Civil chileno. 
relación personal con otra por tiempo indefinido, sin que haya la posibilidad de poner término a la relación"63.

La verdad es que el Código Civil chileno establece algunas hipótesis de irrevocabilidad, por ejemplo, para el acreedor de la diputación para el pago, que es un mandato, si el diputado ha sido designado en el contrato ${ }^{64}$. Tal regla se ha explicado con base en el interés común de las partes en que el mandato subsista, en este caso, porque al acreedor le interesa que otro reciba el pago por él y al deudor que este último se pague y en consecuencia se extinga la obligación.

Luego, a partir de esta situación y otras dispuestas en diversas disposiciones del Código Civil se ha establecido que en algunas situaciones no es necesario expresar la irrevocabilidad porque se subentiende en aquellas situaciones en que el interés del mandatario exige el mantenimiento del mandato. Esto último suele ocurrir en aquellos mandatos que forman un todo inseparable de otros contratos, ya sea porque constituyen el medio para cumplir una obligación contraída o se han dispuesto como una condición en un contrato en el que ambas partes se obligan: en estas situaciones suele aparecer un interés distinto al del mandante. A modo de ejemplo se suele citar, en el Derecho patrimonial, el caso del deudor que debe alimentos y confiere poder irrevocable a su acreedor para que cobre otros créditos, y de esta forma se pueda cubrir la deuda alimenticia, o se otorga un mandato para realizar una solicitud administrativa, en circunstancias que la autorización requerida es la única condición de la cual pende el cumplimiento de otro contrato. En consecuencia, cuando el mandato tiene por objeto satisfacer un interés común de las partes es irrevocable mientras ese interés no se haya realizado ${ }^{65}$.

Además del mandato de interés común, en que la irrevocabilidad se presume, se ha determinado por analogía que es lícito estipular la irrevocabilidad del encargo confiado al mandatario. Se discutió en el pasado su validez, debido a que el Código señala que el mandante puede revocar a su arbitrio el mandato. Actualmente la comprensión de la norma ha sido que es disponible por las partes, aceptándose, de esta manera, la validez del pacto de irrevocabilidad en la medida que haya interés legítimo en ella ${ }^{66}$. Por último, se arguye que la ley no

63 Orrego, J., $2017,27$.

64 Artículos 1584 y 1585 del Código Civil chileno.

65 GonzÁlez, Joel, "Mandatos irrevocables: un cuestionamiento a su general aceptación”, Revista Chilena de Derecho, vol. 44, n. ${ }^{\circ}$ I, 2017 , 40. Barros, Enrique, "Mandato Civil", Apuntes Universidad de Chile, 53, Santiago, 20 io. Barcia, Rodrigo, De las fuentes de las obligaciones, t. II, Santiago, Editorial Jurídica de Chile, r 23.

66 Respecto de la irrevocabilidad, se ha sostenido que se puede pactar. Así, la Corte a propósito de una persona de avanzada edad que firmó un mandato señaló que "en este caso resulta irrelevan-

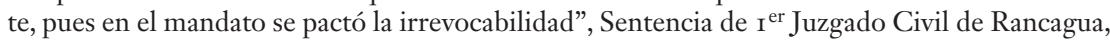
I3 de mayo de 20I4. En el mismo sentido, causa 5868/20 5 (Casación). Resolución I36482 de Corte Suprema, Sala Primera (Civil) de 8 de septiembre de 20r 5. También, se ha accedido a que se declare la irrevocabilidad debido a que el mandato se ha conferido no solo en interés del 
lo prohíbe; por el contrario, el artículo i 2 del Código Civil autoriza la renuncia de los derechos conferidos por las leyes, con tal que solo miren al interés del renunciante ${ }^{6}$.

De acuerdo con lo anterior, por ejemplo, en el caso del mandato para atender a la gestión del patrimonio o al cuidado de la persona para cuando no sea capaz, podría aventurarse que la circunstancia de la incapacidad constituye la condición de la cual pende el cumplimiento del contrato y que si además existe un interés común, sea cualquiera, la irrevocabilidad pasaría a ser un elemento de la naturaleza del mandato y la revocación tendría lugar solamente en situaciones justificadas.

En seguida, respecto del hecho de que el mandato no podría desplegar su eficacia desde que la incapacidad acaece porque cesa de pleno derecho, primero porque el mandato requiere que el mandante sea capaz, dado que se reputa que el representado ha manifestado su voluntad por mediación del representante, no siendo el segundo más que el vehículo de la voluntad del primero, y luego porque el artículo 2 I 63 n. ${ }^{\circ} 7$ del Código Civil dispone que termina por interdicción del mandante ${ }^{68}$.

Ello no quiere decir que el régimen de protección no sea posible a través del mandato, debido a que tal fundamento ha sido discutido por la doctrina de la representación modalidad del acto jurídico. En ese sentido, se ha sostenido que no es el mandante quien manifiesta su consentimiento en el momento en que el mandatario lleva a cabo la gestión que se le ha encargado. Es el mandatario quien expresa su propio consentimiento, y no el mandante, aunque los efectos del contrato se radiquen en el último ${ }^{69}$. Al respecto, recuerda Meza Barros que "quien contrata es el mandatario, sin perjuicio que en virtud de la representación el contrato surta efectos respecto del mandante como si él hubiere contratado" 70 .

Adicionalmente, ha de recordarse que del tenor del artículo 2 I 63 del Código Civil se infiere que el mandato no termina por la incapacidad, pues la ley exige

mandante. Causa i83 I3/2016 (Casación). Resolución 5853 I 2 de Corte Suprema, Sala Primera (Civil) de 8 de octubre de 20r6. Por último, se ha indicado que "el mandato irrevocable, que el trabajador confiere a su empleador se rige por el artículo 2 i i 6 y siguientes del Código Civil y por el artículo 24I del Código de Comercio en cuanto a su irrevocabilidad". Causa 305/20 I 5 (Reforma Laboral). Resolución 793 I de Corte de Apelaciones de Temuco, de 29 de enero de 2016.

67 Stitchkin, D., El Mandato Civil, 5. ${ }^{\text {a }}$ edición, Santiago, Editorial Jurídica de Chile, 2009, 462 y 5 I3. Barrientos Grandon, J., El Código Civil, Santiago, Legal Publishing, 20 I3, I 544. Lyon, $2007, \mathrm{I} 84$.

68 "La ley no ha dado reglas especiales, aplicándose en consecuencia las normas generales en materia de capacidad. Tal capacidad, se ha dicho, sería aquella necesaria para celebrar y ejecutar el acto jurídico al que se refiere el mandato, considerando que jurídicamente es el mandante quien contrata, aunque lo haga a través de otra persona". Orrego, J., 20I 7, 3.

69 Artículo I 448 del Código Civil chileno.

70 Meza Barros, R., I995, 355. En el mismo sentido, León, A., La voluntad y la capacidad en los actos jurídicos, Santiago, Editorial Jurídica de Chile, I952, I87. 
que se declare la interdicción. Al respecto, ha señalado Orrego que ello "no parece razonable, si se observa que el mandatario, al concluir su gestión, no podrá rendirle cuenta a su mandante presuntamente incapaz ${ }^{71}$. En dicho momento, necesariamente habría que obtener la interdicción y el nombramiento de un curador que reciba la rendición de cuenta”. Sin embargo, el mandante puede relevar al mandatario de la obligación de rendir cuentas. En efecto, en términos generales, puede el mandante exonerar al mandatario de tal obligación ${ }^{72}$. En consecuencia, aunque se adopte la opción más desfavorable a la continuidad del mandato, este subsiste hasta que se dicte el decreto de interdicción correspondiente.

Finalmente, no se debe dejar pasar el hecho de que así se ha resuelto en la mayoría de los sistemas jurídicos pertenecientes a la tradición romano-germánica; según se ha podido ver, aun cuando se mantiene la regla, se permite que este produzca efectos si la persona así lo ha declarado, esto es, a través de la incorporación de una condición suspensiva de la eficacia del poder conferido en el mandato 73 .

En conclusión, el respeto a la dignidad de la persona, a la autonomía y la determinación, además de los inconvenientes del modelo clásico de protección de la capacidad "interdicción", llevan a considerar como una posibilidad que las personas puedan, en virtud de la autonomía de la voluntad, designar un mandatario para que las sustituya y las represente una vez que pierdan la capacidad de obrar, no obstante las dificultades jurídicas que ello pueda implicar.

\section{Conclusiones}

I. En el Derecho comparado la protección de la capacidad comprende en la actualidad una regulación muy variada en los distintos sistemas jurídicos que se han preocupado de la autonomía e independencia de las personas mayores y, aunque hasta el día de hoy no puede afirmarse que existe acuerdo respecto del régimen más adecuado, los ordenamientos transitan rápidamente por la senda de incorporar en sus legislaciones la protección de los derechos esenciales de las

7i Orrego, J., 20i 7, 3i. En el mismo sentido, Stitchkin, David, El mandato civil, 5. ${ }^{\text {a }}$ edición, Santiago, Editorial Jurídica de Chile, año 2009, 5 I 6.

72 Orrego, J., 2017 , I 7.

73 Callejo, C., "La representación voluntaria del incapaz", Revista Crítica de Derecho Inmobiliario, n. ${ }^{\circ} 7$ I I , 2009, i I 8. Heras, M., "Nuevos instrumentos jurídicos en la protección de las personas incapaces en el ordenamiento jurídico español: hacia una mayor flexibilización de las instituciones tradicionales", IUS, 20 Iо, Iоo. Díez-Picazo, L., La representación en el Derecho Privado, Madrid, Civitas, I979, 74. Pérez de VArgas, J., "La autotutela: una institución a regular por nuestro Código Civil", Revista de Derecho Privado, vol. 85, n. ${ }^{\circ}$ I 2, 200 I, 937-974. Cfr. MuñIz, E., "La incapacidad y las reformas del derecho contractual", Revista de Derecho Privado y Constitución, n. ${ }^{\circ}$ 23, 2009, 287. Fossier, T. (2008/2009), IOI3. 
personas y los principios aludidos, ahora contenidos en la tratados suscritos por cada uno de ellos.

2. ${ }^{\circ}$ El sistema chileno no ha examinado la posibilidad de proteger la capacidad a través de la autonomía de la voluntad como alternativa a la incapacitación de la persona e institución prioritaria a la curatela.

$3 .{ }^{\circ}$ Una persona capaz sí puede designar a otra para que la represente cuando no pueda dirigir su vida. El mandato con representación es la técnica contractual idónea para que las personas puedan expresar su voluntad y producir los efectos queridos por las partes frente a un proceso de incapacitación.

$4 .^{\circ}$ Los argumentos esgrimidos para rechazarlo, tales como la pérdida de capacidad del mandante como causa de eficacia de la figura y que una vez que el mandato produzca efectos no podrá ser revocado por el mandante, no han sido suficientemente contundentes para no considerar el mandato como una forma de proteger la capacidad. Lo anterior implica moverse siempre en el ámbito de autonomía de la voluntad, la representación voluntaria y no legal. La fuerza obligatoria de este contrato deriva exclusivamente de la declaración de voluntad del mandante y del mandatario, y no de una posible declaración judicial de incapacidad del mandante, destinada a validar el mandato.

\section{Bibliografía}

Alessandri Besa., A. Nulidad y Rescisión en el Derecho Civil chileno [en línea], Santiago, Ediar, I940, I 296, disponible en http://www.bcn.cl/catalogo/detalle_li bro? bib=32802\&materia=Rescisión [consultado 3 de junio de 20 I 5].

Alessandri Rodríguez, A.; Somarriva Undurraga, M.; Vodanovic H., A., Tratado de Derecho Civil: Partes Preliminar y General, Santiago, Editorial Jurídica de Chile, I998, I 2 I 3.

Barcia Lehmann, R., "Algunas críticas al derecho común y especialmente a la regulación de las incapacidades respecto del adulto mayor en el ordenamiento jurídico chileno", Revista Chilena de Derecho Privado, n. ${ }^{\circ} 23,2014$, 57-86.

Barcia, Rodrigo, De las fuentes de las obligaciones, t. II, Santiago, Editorial Jurídica de Chile, 294 .

Barcia, Rodrigo, "La autonomía privada como principio sustentador de la teoría del contrato y su aplicación en Chile", Cuadernos de Análisis Furídico, n. ${ }^{\circ}$ III, 2006, I 59-1 85 .

Barrientos Grandon, J., El Código Civil, Santiago, Legal Publishing, 20 i 3, 482. 
Barrio, Aurelio, Autonomía privada y matrimonio, Madrid, Reus, 20 I6, 230.

Barros, Enrique, Mandato Civil, Santiago, Apuntes Universidad de Chile, 2oro, 58.

Boyer, P., "Le mandat de protection future", Revue Française de Comptabilité, n. ${ }^{\circ}$ 445,20 I I, I 2-I 3.

Brauer, D., Autonomie und Familie: Behandlungsentscheidungen bei geschäfts-und einwilligungsunfähigen Volljährigen, Berlin, Springer-Verlag, 201 3, 236.

Bürgerliches Gesetzbuch in der Fassung der Bekanntmachung vom 2. Januar 2002 (вяв. I S. 42, 2909; 2003 I S. 738), das zuletzt durch Artikel I des Gesetzes vom i i. März 20 г6 (вяв. I S. 396), \$\$ I773s., I896s., I909s. вяв) [en línea], disponible en https://www.gesetze-im-internet.de/bgb/ BJNROOI950896 [consultado 24 de abril de 20 I6].

Callejo, C., "La representación voluntaria del incapaz", Revista Crítica de Derecho Inmobiliario, n. ${ }^{\circ}$ I I , 2009, 97-I 39.

Cano Martínez de Velasco, J., El poder irrevocable, Barcelona, José María Bosch, I998, I 32 .

Claro Solar, L., Explicaciones del derecho civil chileno y comparado, vol. II, Santiago, Editorial Jurídica de Chile, I992, I678.

Combret, Jacques, Las “personnes vulnérables”, Madrid, Colección Scientia Iuridica, 2010, 77-94.

Conroy, A.J., "Curbing the license to steal: a discussion of english law and possible reforms for the durable power of attorney" [en línea], Real Property, Trust, and Estate Law Fournal, 44 (I), 2009, 31-54, disponible en https://search. proquest.com/docview/208 I63793 ?accountid= 14478 [consultado io de febrero de 2017$]$.

Corral Talciani, H., "Interdicción de personas que sufren trastorno de dependencia a la cocaína”, Revista de Derecho, vol. xxiv, n. ${ }^{\circ}$ 2, 20 I I, 3 I-64.

Cour des comptes La protection juridique des majeurs - septembre 2016 Cour des comptes - www.ccomptes.fr - @Courdescomptes [en línea], 28 y 30, disponible en https://www.ccomptes.fr/.../2016roo4-rapport-protectionjuridiqu. [consultada 22 de febrero de 2017 ]. 
De Amunátegui, C., Incapacitación y mandato, Madrid, La Ley, 2008, $3^{8}$ I.

De Amunátegui, C., "Los poderes preventivos en el Derecho español: luces y sombras", en PÉrez de VARgas, J. (director), La encrucijada de la incapacitación y la discapacidad, Madrid, La Ley, 201 I, 249-283.

De Amunátegui, C., "Los poderes preventivos: un apunte sobre su reciente regulación en los códigos civiles español y francés”, en Familia y discapacidad (coordinadora Díaz, Silvia), Madrid, Colección Scientia Iuridica, 20 Io, 39$5 \mathrm{I}$.

Delfose, Alain y Baillon, Nathalie, La réforme du droit des majeurs protégés, París, Litec, 2009, 336.

De Verda y Beamonte, J., "Estudio de la extinción del mandato desde un punto de vista jurisprudencial", Actualidad furídica Iberoamericana, n. ${ }^{2}$, 201 5, 5 I 7532.

Díez-Picazo, L., La representación en el Derecho Privado, Madrid, Civitas, I979, 324 .

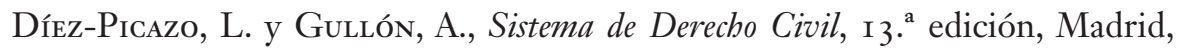
Tecnos, 2016, 460.

Dimond, B., Legal aspects of mental capacity, Great Britain, Blackewell Publishing, 2008, 4I 7 .

Domínguez, A., Derecho Sanitario y responsabilidad médica, 2. ${ }^{\text {a }}$ edición, Valladolid, Lex Nova, 2007, 864 .

Domínguez Águila, R., Teoría general del negocio jurídico, 2. a edición, Santiago, Editorial Jurídica de Chile, 20 2, 253.

Dworkin, R., El imperio de la justicia, 2. a edición, Barcelona, Gedisa, I992, 328.

Dworkin, R., Los derechos en serio, Barcelona, Ariel, 20 I 2, 5 I 2.

Faupel, F., Die Betreuungsverfügung. Ein Instrument zur privatautonomen Ausgestaltung der gesetzlichen Betreuung [en línea], Universitätsverlag Göttingen, 20 Iо, I 80, disponible en http://d-nb.info/ı I I $8668225 / 34$ [consultado 24 de abril de 20r6]. 
Figueroa, G., El Patrimonio, Santiago, Editorial Jurídica de Chile, i 99 I, 66r.

Figueroa, Marta, Autonomía de la voluntad, Puerto Rico, Dykinson, 20 i6, 4I8.

Fossier, T., "Protection du majeur vulnérable", en Murat, P. (director), Droit de la famille, París, Dalloz, 2008/2009, 97 I-IOI 5.

Galindo, I., "Representación, mandato y poder”, Revista de Derecho Privado, año I, n. ${ }^{\circ}$ I, 2002, I3-22.

Gallego, I., "Consideraciones sobre el mandato de protección futura en el Derecho francés. Su regulación”, en Pérez de VArgas, J. (director), La encrucijada de la incapacitación y la discapacidad, Madrid, La Ley, 20 I I, 285-330.

García V., E., La tutela de la propia incapacidad, México, Instituto de Investigaciones Jurídicas, unAM, $2007,306$.

González, Joel, "Mandatos irrevocables: un cuestionamiento a su general aceptación”, Revista Chilena de Derecho, vol. 44, n. ${ }^{\circ}$ I, 20I 7, 35-37.

GonzÁlez, O., “¿Tiene sentido la incapacitación de los enfermos mentales?”, Revista de la Asociación Española de Neuropsiquiatría, vol. 26, n. ${ }^{2}$ 2, 2006, 407-4I 5.

Grimaldi de Caldera, E. y Bilbao de Romero, G., "El enfermo mental en nuestro ordenamiento jurídico", Revista de la Facultad de Derecho de la Universidad de Carabobo, I990, 45-85.

Hack, J., Buecking, B., López, C. L., Ruchholtz, S., Kühne, C. A., "Patientenverfügung, Vorsorgevollmacht und gesetzliche Betreuung im unfallchirurgischen Alltag Zahlen aus einem alterstraumatologischen Zentrum”, Zeitschrift für Gerontologie und Geriatrie, vol. 49, n. ${ }^{\circ}$ 8, 2016, 72 I-726.

Hack, J., Buecking, B., López, S., Ruchholtz, C. L., Kühne, C. A., "Vorausverfügungenimklinischen Alltag Patientenverfügung, Vorsorgevollmacht und Betreuungsverfügung", DerUnfallchirurg, n. ${ }^{\circ}$ 2, 20 I 7, I 53-г6 I.

Hart, H. L. A., The Concept of Law, Oxford University Press, Carrio G. (traductor), Buenos Aires, Abeledo Perrot, I961, 332.

Hart, H. L. A., The Concept of Law, $2^{\text {nd }}$ edition, Oxford, Clarendon Press, I99I, 309. 
Henríquez, I., El mandato. Ensayos doctrinarios y comentarios de jurisprudencia, Santiago, Thomson Reuters, 2013, 236.

Heras, M., "Nuevos instrumentos jurídicos en la protección de las personas incapaces en el ordenamiento jurídico español: hacia una mayor flexibilización de las instituciones tradicionales", IUS, 20 I0, 97-I I 2.

IsLER, ÉrIKA, "Los principios en la ley i 9.947: análisis y desarrollo”, Revista Ars Boni et Aequi, n. ${ }^{\circ}$ 5, 2009, 83-I I6 [en línea], disponible en https://dialnet. unirioja.es/descarga/articulo/3257724.pdf [consultado 26 de julio de 201 7 ].

Jenkinson, P. y Hakopian, A., "Mandant de Protection future" [en línea], Explaining France's New, 2010, 62-64, disponible en http://www.americanbar.org/ content/dam/aba/publications/probate_property_magazine/v24/or/20 Io_ aba_rpte_pp_v24_I_article_jenkinson_hapkopian.authcheckdam.pdf [consultado 24 de abril de 2016$]$.

Kelsen, H., Teoría pura del derecho: Introducción a la ciencia del derecho, 2. ${ }^{a}$ edición, México, Universidad Nacional Autónoma de México, I982, 365.

Kelsen, H., Teoría pura del derecho: Introducción a la ciencia del derecho, $4 \cdot{ }^{\mathrm{a}}$ edición, Buenos Aires, Eudeba, I99 I, I 83 .

Ladsous, J., "Les notaires, la loi du 5 mars 2007 et le mandat de protection future", Vie sociale, n. ${ }^{\circ}$ 3, 2010, 61-69.

Lasarte, C., Curso de Derecho Civil patrimonial. Introducción al Derecho, 22. a edición, Madrid, Tecnos, 2016, 488.

Lathrop, F., "Protección jurídica de los adultos mayores en Chile", Revista Chilena de Derecho, vol. 36, n. ${ }^{\circ}$ I, 2009, 77-I I 3 .

LEón, A., La voluntad y la capacidad en los actos jurídicos, Santiago, Editorial Jurídica de Chile, I952, 397.

Lepin, Cristian, Los nuevos principios del Derecho de Familia, Revista Chilena de Derecho Privado, n. ${ }^{\circ}$ 23, 2014, 9-55.

Linacero, María, Tratado de Derecho de Familia, Valencia, Tirant lo Blanch, 20 i6, 893. 
López, JuAN, “Autonomía de la voluntad, poder público y orden constitucional”, en Autonomía de la voluntad en el derecho privado (coord. Prats, Lorenzo), España, Wolters Kluwer, 20 I 2, 8.

Lund, S., "Lasting power of attorney: a significant ethical responsibility", British Journal of Hospital Medicine, vol. 76, n. ${ }^{\circ}$, 2015,5 I 8-522.

Lyon Puelma, A., Personas naturales, $3 \cdot{ }^{\text {a }}$ edición, Santiago, Ediciones Universidad Católica de Chile, 2007, 2 I 5.

Martins, R. "The importance of a Lasting Power of Attorney", Quality in ageing and older adults, vol. I4, n. ${ }^{\circ} 3,2013,2$ I 8-2 20.

Meimon, C., "Le mandat de protection future", Reliance, n. ${ }^{2}$ 28, 2008, i i 8-i I9.

MEJÍA, R., Estipulaciones de autotutela para la propia incapacidad: la penúltima voluntad, Lima, Grijley, 2009, 254.

Meza Barros, R., Manual de Derecho Civil. De las fuentes de las obligaciones, t. I, 8. ${ }^{\text {a }}$ edición, Santiago, Editorial Jurídica de Chile, I995, 4I I.

Morón Kavanagh, M., "La representación en el Derecho Civil Argentino y en el Derecho Civil Alemán”, Revista del Notariado, n. ${ }^{\circ}$ 892, 2007, 95-I 56.

Muñız, E., "La incapacidad y las reformas del derecho contractual”, Revista de Derecho Privado y Constitución, n. ${ }^{\circ}$ 23, 2009, 285-334.

Muñız, E., "La incapacidad y las reformas del derecho contractual”, Derecho Privado y Constitución, n. ${ }^{\circ}$ 23, 2009, 285-334.

Noguéro, David, "Priorité du mandat de protection future et réflexion sur sa publicité, son homologation, sa validité et sa révocation" (IDS - UMR- INSERM I I45) [en línea] 2OI4, disponible en http://www.davidnoguero.com/ wp-content/uploads/20 r 6/o I/Mandat-de-protection-future.-Cass-janvier-20I7.pdf [consultado 25 de julio de 2016], I4.

Orrego, J., "El Mandato" [en línea], io, enero, 20I7, disponible en http:s7370 5 fd 5 odada36d.jimcontent.com/download/.../Contrato \% 20 de\% 2oMandato.pdp.3 [consultado i6 de febrero de 20 г 7]. 
Pellier, J. D., "Le mandat de protection future issu de la loi du 5 mars 2007 portant réforme de la protection des majeurs", Les Petites Affiches, n. ${ }^{\circ} 8_{3}$, 2007, 4-6.

Pereña Vicente, M., Dependencia e incapacidad. Libertad de elección del cuidador o del tutor [en línea], Madrid, Universitaria Ramón Areces, 2008, I09, disponible en http://vlex.com/vid/capitulo-iii-poderes-preventivos-2282 I046I [consultado 26 de enero de 2017 ].

Pereña Vicente, M., "Autonomía y voluntad en la dependencia y la incapacidad" [en línea], en Fornadas Dincat Barcelona, 2010, 2, disponible en http://www. dincat.cat/autonomia-i-voluntat-en-la-depend\% $\mathrm{C}_{3} \%$ A8ncia-i-la-incapacitat_57 84 [consultado 8 de mayo de 20r6].

Pérez de VArgas, J., "La autotutela: una institución a regular por nuestro Código Civil", Revista de Derecho Privado, vol. 85, n. ${ }^{\circ}$ I 2, 200 I, 937-974.

Pérez de VArgas, J., "Las reformas del derecho español en materia de autotutela y de poderes preventivos", en Pérez de VArgas, J. (director), La encrucijada de la incapacidad y la discapacidad, Madrid, La Ley, 2 O I I, 5 I-I 23.

Ramos, J. A., "Positivismo jurídico y derechos humanos", en Pérez Bermejo, J. M. y Rodilla González, M. Á. (editores), furisdicción, interpretación y sistema jurídico [en línea], Salamanca, Universidad de Salamanca, 2007, I I I-I35, disponible en https://books.google.cl/books?isbn=8478003789 [consultado 23 de abril de 20r6].

Ramos Pazos, R., Derecho de Familia, 4. ${ }^{\text {a }}$ edición, Santiago, Editorial Jurídica de Chile, $2003,647$.

Ramos Pazos, R., Derecho de Familia, Santiago, 5. ${ }^{\text {a }}$ edición actualizada, Editorial Jurídica de Chile, 2005, 668.

Recover, T., "Hacia la reforma del Código Civil y la Ley de Enjuiciamiento Civil en materia de discapacidad", en García Garnica, M. del C. (director), Nuevas perspectivas del tratamiento jurídico de la discapacidad y la dependencia, Madrid, Dykinson, 2014, I9-29.

Remy, Benjamin, Le mandate en question, Bruxelles, Bruylant, 201 3, 20 Io.

Rojas, V., El concepto de derecho de Ronald Dworkin [en línea], Biblioteca Virtual de Investigaciones Jurídicas de la UNAM, 2006, 4I5, disponible en http://www. 
juridicas.unam.mx/publica/librev/rev/facdermx/cont/.../arti 6 [consultado 23 de abril de 20I6].

Ruz, G., El mandato: ensayos doctrinarios y comentarios de jurisprudencia, Santiago, Thomson Reuters, $2013,232$.

Schopper, A., Patientenverfügung und vorsorgevollmacht. das österreichische patientenverfügungs - und sachwalterrechts-änderungsgesetz 2006, USA y uK, Südwestdeutscher Verlag für Hochschulschriften, 2008, 260.

Soro, Olivier, El principio de la autonomía de la voluntad privada en la contratación: génesis y contenido actual, Madrid, Reus, 2016, 57.

Stitchkin, D., "El Mandato Civil”, Revista de Derecho de la Universidad de Concepción, vol. XII, n. ${ }^{\circ} 47$, I994, $250-274$.

Stitchkin, D., El Mandato Civil, 5. ${ }^{\text {a }}$ edición actualizada por Gonzalo Figueroa Yáñez, Santiago, Editorial Jurídica de Chile, 2009, 534.

VÁsquez Encalada, A., "El fin de la interdicción civil, la reforma de la que nadie está hablando" [en línea], Revista Ideele, n. ${ }^{\circ}$ 250, disponible en http://www. revistaideele.com/ideele/content [consultado I de mayo de 20I6].

Veloso, Paulina, "Nuevos principios del derecho de familia en función, principalmente, de la normativa internacional que emana de los tratados de derechos humanos", Revista de Derecho de la Universidad Católica de Valparaíso, n. ${ }^{\circ}$ XIX, I998, 35-56.

Verdugo, IsMAEL, "La relación entre la autonomía privada y los contratos atípicos”, Revista Ars Boni et Aequi, n. ${ }^{4}$, 2008, Io I- I Io [en línea], disponible en http://www.ubo.cl/icsyc/wp-content/uploads/20 I I/o9/7-Verdugo.pdf [consultado 26 de julio de 2017 ].

Vorsorgevollmachten, und betreuungsverfügungen, Druck: Hausdruckerei, Bremen, 2008, 52, disponible en http://www.jobcenter-bremerhaven.de/ downloads/256/I336r/Broschuere_Vorsorgevollmacht.pdf [consultada 22 de febrero de 2017 ].

Wever, C., "Patientenverfügung, Vorsorgevollmacht und Sterbehilfe", MedR, n. ${ }^{\circ} 29,20$ I I, I $30-140$. 